\title{
On Ditransitive Idioms: \\ With Respect to Korean, Hebrew, and English*
}

\author{
Ju-Eun Lee \\ (Soongsil University)
}

\begin{abstract}
Lee, Ju-Eun. (2017). On Ditransitive Idioms: With Respect to Korean, Hebrew, and English. Language Research, 53.1, 59-101.
\end{abstract}

This paper investigates ditransitive idioms of Korean in comparison with Hebrew and English. It describes the distribution of ditransitive idioms on the basis of fixed- and open-slot dimension, following Mishani-Uval and Siloni (2016), and discusses it in relation to argument structure types, verb types, and the word order. This paper shows that the distribution of idioms is sensitive to verb classification of Rappaport Hovav and Levin (2008) (i.e. give- vs. send-type verbs) in all three languages: Fixed-Goal (Open-Theme) idioms and Full idioms (with Fixed-Goal and Fixed-Theme) occur with send-type verbs only in all three languages. Give-type verbs only occur in Fixed-Theme (Open-Goal) idioms. I propose that an analysis that incorporates the idea of verb-sensitivity in structural terms such as Hallman (2015) can account for the similarities and differences in the distribution of ditransitive idioms across the three languages. In doing so, this paper defends (i) Constituency-based approaches to idiom formation and (ii) the base-generation hypothesis for the word order permutation in Korean ditransitives.

Keywords: ditransitive idioms, fixed-goal idioms, fixed-theme idioms, full idioms, verb-sensitivity, constituency-based approach

\section{Introduction}

This paper provides a description of ditransitive idioms in Korean, comparing them with those of Hebrew and English. We can classify ditransitive

\footnotetext{
* I am very grateful to three anonymous Language Research reviewers for their valuable comments and feedback. I hope that I have done justice to their efforts to improve this work. Any remaining errors are solely mine.
} 
idioms into three subtypes depending on which internal argument position is a fixed or open part of idioms. These are Fixed-Goal (Open-Theme) idioms (e.g., send $x$ to the showers), Fixed-Theme (Open-Goal) idioms (e.g., give $x$ the creeps), and Full idioms (with Fixed-Goal and Fixed-Theme) (e.g., send coals to Newcastle). I examine the distribution of these idioms with respect to argument structure patterns (i.e. Prepositional Dative Constructions (e.g., 'John lent a car to Mary.') or Double Object Constructions (e.g., 'John lent Mary a car.') and verb types (i.e. give-type verbs that are uniformly associated with Caused Possession event, or send-type verbs that may be associated with either Caused Possession or Caused Motion event, according to Rappaport Hovav and Levin's (2008) Verb-Sensitivity approach to dative alternation). I will show that the distribution of three subtypes of idioms show verb-sensitivity like their non-idiomatic literal counterparts. Ditransitive idioms in Korean, Hebrew, and English have much in common. In the proposed analysis, I assume Applicative hypothesis for the structure of Double Object Constructions along the lines of Marantz (1993), and support Hallman's (2015) proposal that there are two different structural sources for Prepositional Dative Constructions that are sensitive to verb types. The present paper also argues for Constituency-based approaches to idiom formation rather than Selection-based approaches.

The rest of the paper is organized as follows. Section 2 describes argument realization patterns for Korean ditransitive verbs and their syntactic structures. Section 3 describes and examines ditransitive idioms along the criteria of fixed- or open-slots, argument realization patterns, and types of verbal heads. Some new observations on Korean are also presented. Section 4 critically reviews previous approaches to idiom formation. Section 5 presents a constituency-based analysis which incorporates Verb-Sensitivity proposal. Finally, section 5 concludes the paper with a brief mention of remaining challenges. 


\section{Ditransitive Verbs in Korean}

\subsection{Argument Realization Patterns}

Korean has two argument realization patterns for ditransitive verbs on the surface. These two patterns are different in Case marking of the Goal argument. In the [Dat $\left.{ }_{\text {Goal }}-\mathrm{Acc}_{\text {Theme }}\right]$ pattern (1a) and the $\left[\mathrm{Acc}_{\mathrm{Goal}}-\mathrm{Acc}_{\mathrm{Theme}}\right]$ pattern (1b), the Goal argument bears the dative case -ey(key)1) and the accusative case -(l)ul, respectively.2) As noted by Y-J Jung and Miyagawa (2004), the $\left[\right.$ Acc $_{\text {Goal }}-A$ Ccc $\left._{\text {Theme }}\right]$ pattern is limited to a small subset of ditransitive verbs (including verbs like cwu-ta ('give'), kaluchi-ta ('teach') and lexical causative verbs like meki-ta ('cause-to-eat', 'feed')). Y-J Jung and Miyagawa (2004) and L Kim (2015) argue that the [Dat ${ }_{\text {Goal }}-$ Acc $_{\text {Theme }}$ pattern and the $\left[\mathrm{Acc}_{\mathrm{Goal}}-\mathrm{Acc}_{\mathrm{Theme}}\right]$ pattern correspond to the Prepositional Dative Construction (e.g., John gave a book to Mary.) and the Double Object Construction (e.g., John gave Mary a book.) of English, respectively.

(1) a. $\left[\mathrm{Dat}_{\mathrm{Goal}}-\mathrm{Acc}_{\text {Theme }}\right]$ pattern

Mina-ka Inho-eykey keyiku-lul cwu-ess-ta.

Mina-Nom Inho-Dat cake-Acc give-Pst-Dec.

'Mina gave a cake to Inho.'

b. $\left[\right.$ Acc $_{\text {Goal }}$-Acc Theme $\left._{\text {Th }}\right]$ pattern

Mina-ka Inho-lul keyiku-lul cwu-ess-ta.

Mina-Nom Inho-Acc cake-Acc give-Pst-Dec.

'Mina gave Inho a cake.'

The Goal argument and the Theme argument show the word order permutation, i.e. they may occur in a reversed word order as well, as we can see in $(2 a)$ and $(2 b)$.

1) -ey and -eykey are glossed 'Dat(ive)' here, as is usual in ditransitive literature, even though they may be a locative preposition as well. -eykey is the form found with animates, contrasting with -ey, which is found with inanimates.

2) In this paper, the following abbreviations are used: Acc (Accusative), Dec (Declarative), Fut (Future), Nmz (Nominalizer), Nom (Nominative), Pst (Past), Top (Topic). 
(2) a. Mina-ka keyiku-lul Inho-eykey cwu-ess-ta. Mina-Nom cake-Acc Inho-Dat give-Pst-Dec.

'Mina gave a cake to Inho.'

b. Mina-ka keyiku-lul Inho-lul cwu-ess-ta. Mina-Nom cake-Acc Inho-Acc give-Pst-Dec.

'Mina gave Inho a cake.'

There is a question of whether two orders in (1) and (2) are derivationally related, and if so, which is the basic. The dominant view seems that the [Theme-Goal] order in (2) is derived from the underlying [Goal-Theme] order in (1) via the scrambling of the Theme over the Goal (Cho 1994; Choi 1999; Lee 2004; Oh and Zubizarreta 2009; L Kim 2015, among others).

\subsection{Asymmetric Syntactic Structures}

English ditransitive constructions are associated with two syntactic structures, the Prepositional Dative Construction (henceforth, the PDC) and the Double Object Construction (henceforth, the DOC). According to previous studies on Korean ditransitives (including Y-J Jung and Miyagawa 2004 and L Kim 2015), Korean ditransitive verbs also have two syntactic structures corresponding to English PDCs and DOCs. Many proposals have been put forth regarding the syntactic structure of these two patterns.

In this paper, I will assume, following previous studies (e.g., L Kim 2015; K-M Kim 2015), Bruening's (2010) Applicative hypothesis, which is built upon ideas in Marantz (1993). The main idea is that the PDC has a simple VP structure (3a) within which both the Theme and the Goal arguments are generated, whereas the DOC has an additional functional layer called ApplP which hosts the Goal argument. In terms of meaning, it is assumed that the PDC conveys Caused Motion (i.e. locative) semantics, and the DOC conveys Caused Possession (i.e. transfer-of-possession) semantics. L Kim (2015), in particular, presents evidence for this structural asymmetry between the PDC and the DOC in Korean 
from quantifier scope and nominalization facts. See Harley and Miyagawa (2017) for a nice summary of other previous proposals such as Larson (1988) and Harley (2002).

(3) a. PDC in Korean

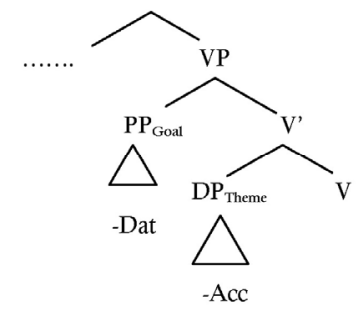

b. DOC in Korean

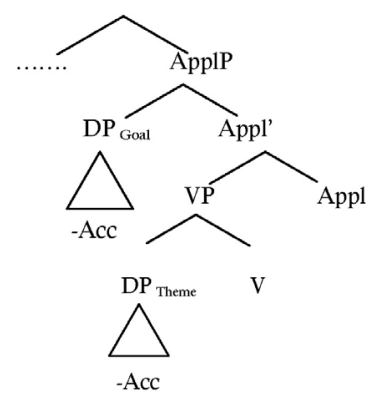

\section{Ditransitive Idioms in Korean:}

\section{a Comparison with Hebrew and English}

3.1. Subtypes of Ditransitive Idioms: Distribution of Fixed- \& Open-Slot Arguments

We can identify three subtypes of ditransitive idioms in Korean on the criterion of the fixed-/open- slot dimension. These are (i) Fixed-Goal (Open-Theme) idioms, (ii) Fixed-Theme (Open-Goal) idioms, and (iii) Full idioms (with Fixed-Goal and Fixed-Theme). In Korean, all three types are attested in the [Dat-Acc] pattern (i.e. PDC), as illustrated in (4)-(6). Some of the examples are taken from Hwang (2015), K-M Kim (2015), and L Kim (2015), and others are collected from Korean 


\section{dictionaries. (I have listed 34 idioms here. The number of Fixed-Theme (Open-Goal) idioms is higher than the others.)}

(4) Fixed-Goal (Open-Theme) Idioms in [Dat-Acc] Pattern:

a. -(l)ul cesung-ey(*key) ponay-ta 'send $\mathrm{x}$ to the other world' (Levin 2010)

An kulemyen nay-ka ne-lul cesung-ey ponay-keyss-ta.

if not-do I-Nom you-Acc other.world-Dat send-Fut-Dec.

'If not, I'll send you to the other world (i.e. kill you).'

b. -(l)ul sonakwi-ey(*key) cwi-ta 'grasp $\mathrm{x}$ into the hand' ' (Hwang 2015)

(Sanghwang-ul cengli-ha-ki wihay), ku-nun ku salam-ul sonakwi-ey

(situation-Acc complete-do-Nmz in.order), he-Top that person-Acc hand-Dat

cwi-eya-hay-ssta.

grasp-must-Pst-Dec.

'To complete the situation, he had to grasp that person (i.e. He had to have power over that person).'

c. -(l)ul kone-ey( $\left.{ }^{*} k e y\right)$ molta (drive $\mathrm{x}$ to the corner, i.e. have $\mathrm{x}$ over a barrel, put $\mathrm{x}$ in a fix) -(l)ul hwangcen-ey( ${ }^{*} k e y$ ) ponayta (send $\mathrm{x}$ to the next world, i.e. kill $\mathrm{x}$ )

-(l)ul ip-ey( $\left.{ }^{*} k e k e y\right)$ tamta (put $\mathrm{x}$ onto the mouth, i.e. mention $\mathrm{x}$, talk about $\mathrm{x}$ )

-(l)ul ekkey-ey(*key) cita (carry $\mathrm{x}$ on the shoulder, i.e. take or assume a responsibility for $\mathrm{x}$ ) -(l)ul maum-ey(*key) twu-ta (put $\mathrm{x}$ on the mind, i.e. keep $\mathrm{x}$ in mind, be attentive to $\mathrm{x}$ )

-(l)ul nwunaph-ey( ${ }^{*} k e y$ ) twu-ta (put $\mathrm{x}$ in front of one's eye, i.e. face $\mathrm{x}$, be very close to reach $\mathrm{x}$ ) -(l)ul son-ey( $\left.{ }^{*} k e y\right)$ neh-ta (put $\mathrm{x}$ in hands, i.e. obtain $\mathrm{x}$ )

-(l)ul kasum-ey(*key) sayki-ta (engrave $\mathrm{x}$ on the chest, i.e. remember $\mathrm{x}$ )

(5) Fixed-Theme (Open-Goal) Idioms in [Dat-Acc] Pattern:

a. -eykey (il)chim-ul noh-ta 'stick/put on a needle on x' (Hwang 2015, K-M Kim 2015)

Sensayngnim-un aitul-eykey (il)chim-ul noh-ass-ta

teacher-Top kids-Dat (one)needle-Acc stick/put.onto-Pst-Dec

'The teacher stuck/put/gave a needle at the kids (i.e. the teacher scolded/warned the kids (to be quiet)).'

b. -eykey kwi-lul cwu-ta 'give $\mathrm{x}$ an ear' (Hwang 2015, K-M Kim 2015)

Na-nun imi ku-eykey kwi-lul cwu-ess-ta

I-Top already he-Dat ear-Acc give-Pst-Dec

'I already gave an ear to him (i.e. I already eavesdropped on him).'

c. -ey(key) yel-ul nay-ta (give/bring out heat to $\mathrm{x}$, i.e. become enthusiastic on $\mathrm{x}$ )

-ey(key) pistay-lul seywu-ta (pop a vein to $\mathrm{x}$, i.e. get furious with anger on $\mathrm{x}$ )

-eykey son-ul namil-ta (hold out/stretch out/ extend a hand on $\mathrm{x}$, i.e. help $\mathrm{x}$ )

-eykey palam-ul neh-ta (put wind into $\mathrm{x}$, i.e. instigate $\mathrm{x}$ )

-eykey ton-ul mek-i-ta (cause $\mathrm{x}$ to eat money/feed $\mathrm{x}$ money, i.e. bribe $\mathrm{x}$ )

-ey(key) tung-ul tolli-ta (turn back to $\mathrm{x}$, i.e. betray $\mathrm{x}$, part from $\mathrm{x}$ )

-eykey hantek-ul sso-ta (shoot one chin to $\mathrm{x}$, i.e. treat $\mathrm{x}$ )

-ey(key) mom-ul pachi-ta (offer body to $\mathrm{x}$, i.e. devote oneself to $\mathrm{x}$ )

-ey(key) chanmwul-ul kkien-ta (put cold water over $\mathrm{x}$, i.e. discourage $\mathrm{x}$ )

-ey pakcha-lul kaha-ta (add spur to $\mathrm{x}$, i.e. give an impetus to $\mathrm{x}$ )

-ey(key) hannwun-ul pal-ta (sell one eye to $\mathrm{x}$, i.e. get sidetracked by $\mathrm{x}$ )

-ey sasung-ul ponay-ta (send a birth date to $\mathrm{x}$, i.e. send a letter of setting a wedding date to $\mathrm{x}$ ) 
-ey mom-ul tenci-ta (throw a body to $\mathrm{x}$, i.e. devote oneself to $\mathrm{x}$ )

$-e y(k e y)$ naksi-lul tenci-ta (throw a bait to $\mathrm{x}$, i.e. deceive $\mathrm{x}$ )

-eykey tol-ul tenci-ta (throw a stone to $\mathrm{x}$, i.e. criticize $\mathrm{x}$ )

$-e y(k e y)$ cwul-ul tay-ta (put/touch a rope to $\mathrm{x}$, i.e. make a connection with $\mathrm{x}$ )

(6) Full Idioms (with Fixed-Goal and Fixed-Theme) in [Dat-Acc] Pattern:

a. ip-ey( $\left.{ }^{*} k e y\right)$ mote-lul tal-ta 'put an electric motor on the mouth' (Hwang 2015)

Thim-i ip-ey mote-lul tal-ass-ta.

Tim-Nom mouth-Dat electric.motor-Acc put.on/hang-Pst-Dec

'Tim put the electric motor on his mouth (i.e. Tim spoke very fast and quickly).'

b. kasum-ey(*key) kal-ul pum-ta 'bear a knife in the chest' (K-M Kim 2015)

Swuni-ka kasum-ey kal-ul pum-ess-ta

Suni-Nom chest-Dat knife-Acc bear-Pst-Dec

'Suni bore a knife in the chest (i.e. cherished resentment).'

c. ip-ey(*key) kemicwul-ul chi-ta (pull spiderweb on the mouth, i.e. starve)

kasum-ey ( $\left.{ }^{*} k e y\right)$ mos-ul pak-ta (hammer a nail on the chest, i.e. break one's heart)

nwun-ey ( $\left.{ }^{*} k e y\right)$ puwl-ul tal-ta (kye-ta) (hang fire/light on the eye, i.e. be very enthusiastic)

pwul-ey(*key) kilum-ul pwus-ta (pour oil onto the fire, i.e. worsen the situation)

On the other hand, the [Acc-Acc] pattern (i.e. the DOC) only has Fixed-Theme (Open-Goal) idioms (8a). Fixed-Goal (Open-Theme) idioms and Full idioms are not available, as shown in (7) and (9). Although not all Fixed-Theme (Open-Goal) idioms in the [Dat-Acc] pattern (5) have counterparts in the [Acc-Acc] pattern, as we can see in the contrast between (8a) and (8b), it appears that, in principle, the [Acc-Acc] pattern may allow Fixed-Theme (Open-Goal) idioms.3)

(7) Fixed-Goal (Open-Theme) Idioms in [Acc-Acc] Pattern:

*/??-(l)ul cesung-ul ponay-ta, *-(l)ul sonakwi-lul cwi-ta, *-(l)ul kone-lul molta, */??- (l)ul hwangcen-ul ponayta, *-(l)ul ip-ul tamta, *-(l)ul ekkey-lul cita, *-(l)ul maum-ul twu-ta, *-(l)ul nwunaph-ul twu-ta, *-(l)ul son-ul neh-ta, *-(l)ul kasum-ul sayki-ta

3) A reviewer notes that the verbs in (7)-(9) which resist the Acc-Acc pattern (i.e. DOC) show the same behavior in non-idiomatic contexts, as we can see below in (i)-(iii): these verbs do not appear in the Acc-Acc pattern (DOC) in non-idiomatic contexts either. This supports the main assumption of the present paper that idioms reflect properties of their literal counterparts.

(i) *-lul hwancen-ul ponay-ta (idiom); *senmwul-ul NewYork-ul ponay-ta 'send the gift to New York'(non-idiom)

(ii) *-lul son-ul namil-ta (idiom); *emma-lul senmwul-ul namil-ta 'stretch out the gift to mom' (non-idiom)

(iii) *ip-ul kemicwul-ul chi-ta (idiom); *pang-ul ketun-ul chi-ta 'draw the curtain in the room' (non-idiom) 
(8) Fixed-Theme (Open-Goal) Idioms in [Acc-Acc] Pattern:

a. -lul (il)chim-ul noh-ta, -lul kwi-lul cwu-ta, -lul palam-ul neh-ta, -lul ton-ul mek-i-ta, -lul chanmwuul kkien-ta, -lul pakcha-lul kaha-ta

b. *-lul yel-ul nay-ta, *-lul pistay-lul seywu-ta, *-lul son-ul namil-ta, *-lul tung-ul tolli-ta, *-lul mom-ul pachi-ta, *-lul hannwun-ul pal-ta

(9) Full Idioms with Fixed-Goal and Fixed-Theme in [Acc-Acc] Pattern:

*ip-ul mote-lul tal-ta, *kasum-ul kal-ul pum-ta, *ip-ul kemicwul-ul chi-ta, *kasum-ul mos-ul pak-ta, *nwun-ul puwl-ul tal-ta, *pwul-ul kilum-ul pwus-ta

What is crucial is that the Goal argument never belongs to the fixed part of idioms in the [Acc-Acc] pattern, as already noted by Hong (1998), L Kim (2015), K-M Kim (2015), and Hwang (2015).

Mishani-Uval and Siloni's (2016) discussion of 55 Hebrew ditransitive idioms such as (10-12) show that Hebrew has the same pattern as Korean. Since Landau's (1994) extensive discussion, it is now a standard view that Hebrew ditransitive verbs exhibit the dative alternation on a par with English: the Theme-Goal order corresponds to the PDC, and the Goal-Theme order to the DOC. In both argument structures, the Goal argument is introduced by dative proclitic le- ('to').4) The word order, not morphological marking of the Goal, correlates with the argument structure type (i.e. PDC or DOC). Fixed-Goal (Open-Theme) idioms are present in the PDC only (10a); Fixed-Theme (Open-Goal) idioms are present in both PDC (11a) and the DOC (11b); Full idioms (with Fixed-Goal and Fixed-Theme) exist only in the PDC (12a). In Hebrew, too, the Goal argument of the DOC does not belong to the fixed part of ditransitive idioms.

(10) Fixed-Goal (Open-Theme) Idioms in Hebrew:

a. ha- more hexzir et dani la- telem. (TH-GL = PDC)

The teacher returned Acc Dani to.the furrow

Idiomatic reading: 'The teacher made Dani return to what is accustomed.'

b. *ha- more hexzir la- telem et dani.

The teacher returned to.the furrow Acc Dani

4) $\mathrm{La}$ - in (10-12) is the combination of le and definite article ('the'). While both Recipient Goal and Spatial Goal non-pronominal arguments can be introduced by the proclitic $l e$-, only the Spatial Goal can alternatively take the preposition el (Misahni-Uval and Siloni 2016:3). This situation is similar to Korean -lo, which I will discuss in 3.2. In the case of Spatial pronominal Goal, el-marking is necessary. 
(11) Fixed-Theme (Open-Goal) Idioms in Hebrew:
a. roš ha- memšala he'evir roš et ha- lapid la- nasi. $($ TH-GL $=$ PDC) head the government passed Acc the torch to.the president Idiomatic reading: 'The prime minister passed responsibility to the president.'
b. roš ha- memšala he'evir la- nasi et ha- lapid. (GL-TH $=$ DOC) head the government passed to.the president Acc the torch

(12) Full Idioms with Fixed-Goal and Fixed-Theme in Hebrew:
a. hosif šemen la- medura $($ TH-GL $=$ PDC) added oil to.the fire
Idiomatic reading: 'worsened a difficult situation via a certain act, added fuel to the fire'
b. */\# hosif la- medura šemen $(\mathrm{GL}-\mathrm{TH}=\mathrm{DOC})$ added to.the fire oil

As for English, different studies have reported different observations. Here, I summarize previous remarks on English ditransitive idioms comprehensively. Emonds (1972) first observed the existence of Fixed-Goal (Open-Theme) idioms such as (13a). Harley (2002), among others, points out that Fixed-Goal (Open-Theme) idioms do not occur in the DOC, as (13b) shows. In the case of Fixed-Theme (Open-Goal) idioms, they can be found in the DOC, as shown in (14a) (See Larson 1988, Richards 2001, and Harley 2002). Harley (2002) takes Fixed-Theme (Open-Goal) idioms to be restricted to the DOC, and argues that PDC alternants such as $\left(14 \mathrm{a}^{\prime}\right)$ are not available unless there is a prosodic manipulation. However, Rappaport Hovav and Levin (2008) and Bruening (2010) show that Harley is wrong. In particular, Rappaport Hovav and Levin (2008) note that examples such as (14a') do exist even when they are not prosodically manipulated by Heavy NP-Shift of the Goal argument. Bruening (2010) also observes that (i) Fixed-Theme (Open-Goal) idioms such as (14b) are found in English, although he uses different classification for ditransitive idioms5); and that (ii) this idiom type is generally available in both the PDC and the DOC, as we can see in (14a,a'), (14c) and (14c'). To sum, in English, Fixed-Theme (Open-Goal) idioms are available

5) Bruening (2010:536) uses the following classification: Class 1 (V NP NP, give $X$ the creeps), Class 2 ( $\mathrm{V} \mathrm{NP}$ to $\mathrm{NP}$, give rise to $X$ ), Class 3 ( $\mathrm{V} \mathrm{NP}$ to $\mathrm{NP}$, send $\bar{X}$ to showers), Class 4 (V NP NP, nonexistent). His Class 1 corresponds to our Fixed-Theme (Open-Goal) idioms in the DOC, Class 2 to Fixed-Theme (Open-Goal) idioms in the PDC, Class 3 to Fixed-Goal (Open-Theme) idioms in the PDC, and Class 4 to Fixed-Goal (Open-Theme) idioms in the DOC. 
in both the PDC and the DOC. As for Full idioms, only two examples such as 'give the devil his due' and 'send coals to Newcastle' are found in the literature. Bruening (2010: 536, footnote 14) doubts the claim that give the devil his due is a Full idiom, because one can also say "...You've got to give him his due," with no notion that him is the devil. He concludes that "the idiom is just give $X\left(X^{\prime} s\right)$ due, with the devil being used in its very common metaphorical sense (a miscreant)." If so, it is an example of Fixed-Theme (Open-Goal) idiom in the DOC, belonging to (14a). The other example is send coals to Newcastle. Bruening mentions that "...carry coals to Newcastle is also possible, so the particular verb is not really part of this idiom (only the semantic notion of caused transfer of location is)." However, the notion of caused transfer is conveyed through the verb, and send and carry do not belong to give-type verbs and behave similarly to each other in that they can denote Caused Motion event meaning (in Verb-Sensitivity approach of Rappaport Hovav and Levin 2008, as we will see in the following section 3.2). So, I suggest that 'send/carry coals to Newcastle' is an example of Full idioms in English.

(13) Fixed-Goal (Open-Theme) Idioms in English:

a. send $x$ to the showers, take $x$ to the cleaners, throw $x$ to the wolves, carry $x$ to extremes... (PDC)

b. *send the showers $x$, "take the cleaners $x$, *throw the wolves $x$, *carry extremes $\mathrm{X} \cdot$... (DOC: unattested)

(14) Fixed-Theme (Open-Goal) Idioms in English:

a. give $x$ the creeps, give $x$ the boot, give $x$ the sack, give $x$ the cold shoulder … (DOC)

a'. give the creeps to $x$, give the boot to $x$, give the sack to $x \cdots(\mathrm{PDC})$

b. give rise to $x$, give it to $x$ (PDC) (No DOC alternants; very rare)

c. read $x$ the riot act/read the riot act to $x$, lend $x$ a hand/lend a hand to $x$, lend $x$ a sympathetic ear/lend a sympathetic ear to $x$, give $x$ a wide berth/give a wide berth to $x$, give $x$ the cold shoulder/give the cold shoulder to $x$, show one's card to $x /$ show $x$ one's card, promise $x$ the moon/promise the moon to $x$ (PDC/DOC alternants available) 
c'. give the lie to $x$ (preferred)/give $x$ the lie, give birth to $x$ (preferred)/give $x$ birth, give way to $x$ (preferred)/give $x$ way (PDC/DOC alternants available but PDC preferred)

(15) Full Idioms with Fixed-Goal and Fixed-Theme in English: send/carry coals to Newcastle

The distribution of ditransitive idioms in Korean, Hebrew, and English is summarized below in (16) and (17). In Korean, the Goal and the Theme exhibit word order permutation, as we saw in (1) and (2). As (16) shows, the distribution of Korean ditransitive idioms is sensitive not only to the argument structure type but also to the word order of internal arguments. I will discuss this word order constraint (i.e. linear adjacency requirement between the verb and the fixed argument) in section 4.3.2 and 5 .

(16) Idiom Types in Korean Ditransitives (to be elaborated) a. PDC:

\begin{tabular}{|c|c|c|}
\hline Idiom Type & $\begin{array}{c}{\left[\mathrm{Dat}_{\text {Goal }}-\mathrm{Acc}_{\text {Theme }}\right]} \\
\text { Order (=PDC) }\end{array}$ & $\begin{array}{c}{\left[\mathrm{Acc}_{\text {Thememe }}-\mathrm{Dat}_{\text {Goal }}\right]} \\
\text { Order }(=\mathrm{PDC})\end{array}$ \\
\hline $\begin{array}{c}\text { Fixed-Goal } \\
\text { (Open-Theme) }\end{array}$ & * & $\sqrt{ }$ \\
\hline $\begin{array}{l}\text { Fixed-Theme } \\
\text { (Open-Goal) }\end{array}$ & $\sqrt{ }$ & * \\
\hline $\begin{array}{l}\text { Full (Fixed-Goal, } \\
\text { Fixed-Theme) }\end{array}$ & $\sqrt{ }$ & * \\
\hline
\end{tabular}

b. DOC:

\begin{tabular}{ccc}
\hline Idiom Type & $\begin{array}{c}{\left[\text { Acc }_{\text {Goal-Acc }} \text { Theme }\right.} \\
\text { Order }(=\mathrm{DOC})\end{array}$ & $\begin{array}{c}{\left[\text { Acc }_{\text {Theme-Acc }} \text { Goal }\right.} \\
\text { Order }(=\mathrm{DOC})\end{array}$ \\
\hline $\begin{array}{c}\text { Fixed-Goal } \\
\text { (Open-Theme) }\end{array}$ & $*$ & $*$ \\
\hline $\begin{array}{c}\text { Fixed-Theme } \\
\text { (Open-Goal) }\end{array}$ & $\sqrt{ }$ & $*$ \\
\hline $\begin{array}{c}\text { Full (Fixed-Goal, } \\
\text { Fixed-Theme) }\end{array}$ & $*$ & $*$ \\
\hline
\end{tabular}


(17) Idiom Types in Hebrew and English Ditransitives (to be elaborated)

\begin{tabular}{ccc}
\hline Idiom Type & $\begin{array}{c}\text { TH-GL order } \\
(=\mathrm{PDC})\end{array}$ & $\begin{array}{c}\text { GL-TH order } \\
(=\mathrm{DOC})\end{array}$ \\
\hline \hline Fixed-Goal (Open-Theme) & $\sqrt{ }$ & $* / ? ?$ \\
\hline Fixed-Theme (Open-Goal) & $\sqrt{ }$ & $\sqrt{ }$ \\
\hline $\begin{array}{c}\text { Full (Fixed-Goal, } \\
\text { Fixed-Theme) }\end{array}$ & $\sqrt{ }$ & $* / ? ?$ \\
\hline
\end{tabular}

To conclude, there is a cross-linguistically common flavor in ditransitive idioms on the dimension of fixed-/open-slots in the PDC and the DOC. In all three languages, the DOC has only Fixed-Theme (Open-Goal) idioms. The Goal argument of the DOC does not participate in idiom formation at all in these languages. The PDC, on the other hand, has both Fixed-Goal (Open-Theme) and Fixed-Theme (Open-Goal) idioms. In addition, Full idioms are also possible in the PDC.

\subsection{Types of Verbal Heads}

Now, let's consider ditransitive idioms in terms of verb types involved. Rappaport Hovav and Levin (2008) propose a Verb-Sensitivity approach to dative alternation between the PDC and the DOC in English. Their idea is that ditransitive verbs are not all uniform, and the dative alternation is sensitive to verb types. In their approach, give-type verbs (or core dative verbs, e.g., give, sell, promise, lend, show, etc.) denote only a Caused Possession event meaning (i.e. transfer of possession to Goal-Recipient/ Possessor) in both the PDC and the DOC, whereas send-type verbs (or noncore dative verbs e.g., send, hand, mail, kick, carry, etc.) denote either Caused Possession or Caused Motion (change of location) event meaning, as summarized in (18).6) As throw-type verbs (i.e. verbs of instantaneous

6) Rappaport Hovav and Levin (2008) show that give-type verbs and send-type verbs are different in terms of the (in)ability to question the to-phrase with the question word where, as in (i). Unlike send-type verbs, give-type verbs cannot select spatial prepositions other than to, as in (ii), nor take a source phrase, as in (iii).

(i) (In)ability to question the to-phrase with where (cited from Levinson 2005):

a. To whom/where did you throw/send the ball? (send-type) 
causation of ballistic motion, e.g., fling, kick, shoot, toss, etc.) largely pattern with send-type verbs, they are taken to represent one type. In other words, send- (and throw-) but not give-type verbs may take Spatial Goals.

(18) A Summary of Verb-Sensitivity Approach

\begin{tabular}{clc}
\hline & $\begin{array}{c}\text { Dative Frame } \\
\text { (PDC) }\end{array}$ & $\begin{array}{c}\text { Double Object Frame } \\
\text { (DOC) }\end{array}$ \\
\hline \hline give-type verbs & Caused Possession & Caused Possession \\
\hline $\begin{array}{c}\text { send-type verbs } \\
\text { (including throw-type) }\end{array}$ & $\begin{array}{c}\text { Caused Possession } \\
\text { or Caused Motion }\end{array}$ & Caused Possession \\
\hline
\end{tabular}

Rappaport Hovav and Levin (2008) and Levin (2010) show that fixed arguments of English ditransitive idioms conform to Verb-Sensitivity approach, just like their non-idiomatic literal counterparts: As for Fixed-Goal (Open-Theme) idioms (13), verbal heads must be send-type verbs that may host Spatial Goals in the PDC-type argument structure (e.g., send $x$ to the showers, send $x$ to the devil, take $x$ to the cleaners, push $x$ to the edge, carry $x$ to extremes, throw $x$ to the wolves, etc.), and should never involve give-type verbs, as Fixed-Goal (Open-Theme) idioms do not involve a relation of possession (cf. O'Grady 1998); In Fixed-Theme (Open-Goal) idioms (14), give-type verbs (such as give, lend, show, read, promise) are involved with a Recipient/Possessor Goal, and convey a Caused Possession meaning in both the DOC and the PDC alike. The single example of Full idioms in (15) has send or carry in the PDC.

In the case of Hebrew, Mishani-Uval and Siloni (2016) classify ditransitive verbs into three types based on the distribution of -le and -el, following Francez (2006): Caused Possession/give-type verbs (i.e. Hebrew verbs corresponding to give, show, promise, sell, etc.), canonical Caused

b. To whom $/{ }^{*}$ where did you give the ball? (give-type)

(ii) (In)ability to select spatial prepositions beside to:

a. Fred threw/sent the ball under the porch/behind the tree/over the fence. (send-type)

b. *Fred gave the ball at/behind/over Mary. (give-type)

(iii) (In)ability to take a source phrase:

a. Jill threw/sent the ball from home plate to third base. (send-type)

b. *Josie gave/offered the tickets from Marla to Bill. (give-type) 
Motion verbs (i.e. Hebrew verbs corresponding to put into, let in, push, add, etc.), and Ambiguous verbs/send-type verbs (i.e. Hebrew verbs corresponding to send, throw, return, etc.) with both meanings. They also show that Fixed-Goal (Open-Theme) idioms appear with Caused Motion verbs or Ambiguous verbs (specifically, send-type verbs when they occur with inanimate Spatial Goals in the PDC); Fixed-Theme (Open-Goal) idioms appear with Caused Possession verbs (give-type verbs) or Ambiguous verbs (specifically, send-type verbs when they occur with animate Recipient Goals) in both the PDC and the DOC; Full idioms appear with Caused Motion verbs or Ambiguous verbs (i.e. send-type verbs when they occur with inanimate Spatial Goals in the PDC).

To sum up, both in Hebrew and English, Fixed-Goal (Open-Theme) idioms and Full idioms are associated with the PDC (in the Theme-Goal order) and with verbal heads denoting Caused Motion meaning (including send-type verbs). Fixed-Theme (Open-Goal) idioms are associated with the PDC (in the Theme-Goal order) or the DOC (in the Goal-Theme order) and with verbs denoting Caused Possession meaning (including give-type verbs), as summarized in (19).

(19) Hebrew and English

\begin{tabular}{cccc}
\hline Idiom Type & $\begin{array}{c}\text { TH-GL order } \\
\text { (PDC) }\end{array}$ & $\begin{array}{c}\text { GL-TH order } \\
\text { (DOC) }\end{array}$ & Verbal Head \\
\hline \hline $\begin{array}{c}\text { Fixed-Goal } \\
\text { (Open-Theme) }\end{array}$ & $\sqrt{ }$ & $* / ? ?$ & $\begin{array}{c}\text { Caused Motion; or } \\
\text { send-type verbs } \\
\text { (with Spatial Goal) }\end{array}$ \\
\hline $\begin{array}{c}\text { Fixed-Theme } \\
\text { (Open-Goal) }\end{array}$ & $\sqrt{ }$ & $\sqrt{ }$ & $\begin{array}{c}\text { give-type verbs; or } \\
\text { send-type verbs } \\
\text { (with Recipient Goal) }\end{array}$ \\
\hline Full & $\sqrt{ }$ & $* / ? ?$ & $\begin{array}{c}\text { Caused Motion; or } \\
\text { send-type verbs } \\
\text { (with Spatial Goal) }\end{array}$ \\
\hline
\end{tabular}

Hwang (2015), following Levin (2010), argues that Korean ditransitive idioms are also subject to Verb-Sensitivity by presenting Fixed-Goal (Open-Theme) idioms like (4a) with the verb ponayta ('send') and Fixed-Theme (Open-Goal) idioms like (5b) with the verb cwuta ('give') 
above. However, she does not discuss and investigate verbs other than give and send themselves.

Let's examine Korean ditransitive verbs in terms of verb types more carefully by looking into the list of verbs used in ditransitive idioms in (4)-(6). First, the verbs in (20)-(22) are verbal heads used in three types of ditransitive idioms in Korean.

(20) Fixed-Goal (Open-Theme) Idioms:

ponay-ta (send), cwui-ta (grasp), mol-ta (drive), tam-ta (put.into/onto), ci-ta (carry), twu-ta (put), nehta (put.into), sayki-ta (engrave) …

(21) Fixed-Theme (Open-Goal) Idioms:

noh-ta (stick, put.onto), cwu-ta (give), nay-ta (give, bring out), seywu-ta (pop), namil-ta (extend, stretch out), neh-ta (put.into), meki-ta (cause to eat, feed), tolli-ta (turn), sso-ta (shoot), pachita (offer), kkien-ta (pour), kaha-ta (add), pal-ta (sell), tenci-ta (throw), tay-ta (put, touch) $\cdots$

(22) Full Idioms (with Fixed Goal and Fixed Theme):

tal-ta (put.onto, hang), pwum-ta (bear), chi-ta (pull, draw), pak-ta (hammer), pwus-ta (pour) …

Regarding diagnostics for give-type verbs vs. send-type verbs, Levin (2010:8) proposes the distribution of -lo (which denotes the direction 'to, toward, (heading) for'), as one of the tests for Spatial Goals, following Sohn (1994) and Son (2006). In clear spatial uses, -eykey (used with animates) may be suffixed by $-l o$, whereas -ey, the dative found with inanimates, alternates with $-l o$, as shown in (23a) and (23b).

(23) a. na-nun Swuni-eykey-(lo) ka-ss-ta.

I-Top Suni-Dat-(LO) go-Pst-Dec

'I went to Suni.'

b. na-nun kakey-ey/-lo ka-ss-ta.

I-Top store-Dat/-LO go-Pst-Dec

'I went to the store.'

Levin (2010:8) shows that -eykey can be suffixed by -lo with ponay ('send'), 
but not cwu ('give),' as we can see in (24a) and (24b).

(24) a. na-nun Swuni-eykey-lo sopho-lul ponay-ss-ta.

I-Top Suni-Dat-LO package-Acc send-Pst-Dec

'I sent the package to Suni.'

b. na-nun Swuni-eykey(-*lo) sopho-lul cwu-ess-ta.

I-Top Suni-Dat-LO package-Acc give-Pst-Dec

'I gave a package to Suni.'

Give-type verbs disallow inanimate Goals7) which are marked with -ey (25b). Neither the dative marker -ey nor spatial goal marker -lo is allowed for give (25b), whereas, send allows inanimate Goals with either -ey or $-l o$, as shown in (25a).

(25) a. na-nun Tokyo-ey/-lo sopho-lul ponay-ss-ta.

I-Top Tokyo-Dat/-LO package-Acc send-Pst-Dec

'I sent the package to Tokyo.'

b. na-nun Tokyo-*ey/-*lo sopho-lul cwu-ess-ta.

I-Top Tokyo-Dat/-LO package-Acc give-Pst-Dec

'I gave the package to Tokyo.' (intended)

To recap, give-type verbs denoting possessive semantics allow only -eykey marking with animate (i.e. Recipient/Possessor) Goals, and disallow -eykey-lo, -ey, and -lo markings. Send-type verbs, on the other hand, allow

7) English give-type verbs disallow inanimate Goals in both the DOC (ia) and the PDC (ib), whereas send-type verbs allow inanimate Goals in the PDC (iib), although they also disallow them in the DOC (iia).

(i) a. I gave $\sqrt{ }$ Mary/*the cupboard the dishes.

b. I gave the dishes $\sqrt{ }$ to Mary/*to the cupboard.

(ii) a. I sent $\sqrt{ }$ Mary $/ *$ the border a package.

b. I sent a package $\sqrt{ }$ to Mary $/ \sqrt{ }$ to the border.

When the Theme is an abstract Theme (which is necessarily inanimate), both the PDC and the DOC are possible. For example, 'The new spray cleaner gave a streaked appearance to the mirror in the bedroom.; The new spray cleaner gave the mirror in the bedroom a streaked appearance.). Levin (2010:10) notes that unlike examples with concrete Themes, this kind of examples has a 'cause to come into existence' reading, and concomitantly, lacks a source of transfer. In these cases, inanimate Goals are possible. 
$-e y k e y(-l o),-e y$, and/or $-10,8)$ which suggests that the Goal argument of Korean send-type verbs is a Spatial Goal, be it animate or inanimate. Crucially, Korean send-type verbs are different from English send-type verbs in that they cannot appear in the canonical DOC pattern (i.e. the Acc-Acc pattern) with Caused Possession semantics (e.g., *Mary-ka John-ul/ Tokyo-lul sopho-lul ponay-ess-ta.). Korean send-type verbs only have Caused Motion meaning.9) Rappaport Hovav and Levin (2008) seem to be right in distinguishing two possible interpretations (i.e. Caused Possession and Caused Motion) for English send-type verbs in the PDC. Hallman (2015), to which we turn in section 5.1, suggests an analysis where English PDCs with Caused Possession meaning are derived from their DOC counterparts, hence they can be associated with Caused Possession meaning. However, such derivation is not possible with Korean send-type verbs, as they can never occur in the DOC (i.e. Acc-Acc pattern). I assume that Korean give-type verbs have Caused Possession meaning in the PDC (like their English counterparts), whereas Korean send-type verbs have only Caused Motion meaning in the PDC (unlike English). Verbs of putting can be taken as one of the Caused Motion verbs in that they denote locative semantics and require simple VP structure (See Hallman 2015, among others), but they usually can occur with -ey but not with -lo. (e.g., $X$-lul Z-ey/*-lo nohta: cause $\mathrm{X}$ to be located at Z). Whereas an alternative -lo marking may be a further indication for Spatial Goals, the lack of -lo marking does not rule out the possibility that the Goal is spatial.

Applying these morphological marking diagnostics to verbs in (20-22), I suggest the following classification of verbs in (26). First of all, Korean ditransitive verbs are also subject to Verb-Sensitivity. In non-idiomatic contexts, give-type verbs (e.g, Korean verbs corresponding to give, sell, etc.) only occur with animate Goals (with -eykey marking), whereas

8) Levin (2010) gives the following list of give- and send-type verbs in Korean:

(i) give-type verbs: cwu 'give', kennay 'hand', pal 'sell', pillye cwu 'lend', yaksokha 'promise'...

(ii) send-type verbs: ponay 'send', pwuchi 'mail', cha 'kick', chi 'hit', tenci 'throw', centalha 'forward'...

9) I treated Korean send-type verbs on a par with English send -type verbs in the earlier draft. Two reviewers corrected me about the interpretation property of send-type verbs in Korean. I gratefully acknowledge their comment. 
send-type verbs (e.g., Korean verbs corresponding to send, shoot, etc.) may occur with either animate or inanimate Goals. Certainly, there are other canonical Caused Motion/locative verbs that can only occur with inanimate Goals (e.g., Korean verbs corresponding to put into/onto, hang, pour, etc.).

Secondly, when these verbs are used in idioms, we can observe that Fixed-Goal (Open-Theme) idioms and Full idioms involve send-type verbs and other Caused Motion verbs, which have Spatial Goals. Although send-type verbs may take either animate or inanimate Goals in non-idiomatic contexts, these verbs occur with inanimate Goals only in idioms. What is crucial here is that as Rappaport Hovav and Levin (2008) note, when the Goal is fixed part of idioms, give-type verbs do not appear as the verbal head, whereas send-type verbs and canonical Caused Motion verbs are found.

Thirdly, Fixed-Theme (Open-Goal) idioms, on the other hand, may involve give-type verbs (such as cwu-ta, meki-ta, pal-ta) or send-type verbs (such as kkien-ta, pachi-ta, sso-ta, tenci-ta) or even Caused Motion-only verbs (such as -seywu-ta and neh-ta). This shows that Hwang's (2015) claim that only give-type verbs occur in Fixed-Theme (Open-Goal) idioms is incorrect. Besides, in non-idiomatic contexts, Caused Motion verbs occur with inanimate Goals only; send-type verbs may occur with either animate or inanimate Goals; give-type verbs occur with animate Goals only. However, Fixed-Theme (Open-Goal) idioms may occur with either animate or inanimate Goals depending on individual verbs. Some send-type verbs occur only with animate Goals, whereas other send-type verbs may occur with inanimate Goals as well in idioms. Caused Motion verbs (like seywu-ta ('pop', 'set up') and neh-ta ('put into')) that do not take animate Goals may take them in idioms unlike their non-idiomatic counterparts. It also appears that a give-type verb like pal-ta may have an inanimate Goal in idioms (e.g., cangnankam-ey hannwun-ul pal-ta 'toy-Dat one.eye-Acc sell'). So, although send- and give-type verbs are sensitive to animacy of the Goal in non-idiomatic contexts, they show freer behavior regarding animacy of the Goal in idioms: when the Goal is an open slot in idioms, the Goal can be either animate or inanimate. ${ }^{10)}$ But, still, give-type verbs 
are only found in Fixed-Theme (Open-Goal) idioms.

This array of verb types show that Korean behaves differently from Hebrew and English when the Goal position is an open-slot. In Hebrew and English, only verbs with animate Recipient Goals participate in Fixed-Theme (Open-Goal) idioms, and there is a PDC/DOC alternation with same verbs. The verbal heads behave the same way in idiomatic and non-idiomatic contexts in Hebrew and English. In Korean, however, Fixed-Theme (Open-Goal) idioms are not as sensitive to verb types or animacy of the Goal as Hebrew and English, although give-type verbs still only occur in this type of idioms only.

(26) Verb Types: Korean

\begin{tabular}{|c|c|c|c|c|c|}
\hline \multirow{2}{*}{ Idiom Type } & \multirow{2}{*}{ Verbs } & \multicolumn{2}{|c|}{$\begin{array}{l}\text { In Non-Idiomatic } \\
\text { Contexts }\end{array}$} & \multirow{2}{*}{ In Idioms } & \multirow{2}{*}{ Verb Type } \\
\hline & & $\begin{array}{c}\text {-eykey } \\
\text { (Animate) }\end{array}$ & $\begin{array}{c}-e y \\
\text { (Inanimate) }\end{array}$ & & \\
\hline \multirow{8}{*}{$\begin{array}{l}\text { Fixed-Goal } \\
\text { (Open-Theme) }\end{array}$} & cwui-ta & $\begin{array}{c}* \\
\left({ }^{*} \text { eykey-lo) }\right.\end{array}$ & $\begin{array}{c}\sqrt{ } \\
\left({ }^{*}-l o\right)\end{array}$ & \multirow{8}{*}{$\begin{array}{c}\text { Fixed-Goals: } \\
\text { Only } \\
\text { Inanimate } \\
\text { Goals }\end{array}$} & \multirow{6}{*}{$\begin{array}{c}\text { Caused } \\
\text { Motion } \\
\text { verbs }\end{array}$} \\
\hline & tam-ta & $\begin{array}{c}* \\
\left({ }^{*} \text { eykey-lo }\right)\end{array}$ & $\begin{array}{c}\sqrt{ } \\
(*-l o)\end{array}$ & & \\
\hline & $c i-t a$ & $\begin{array}{c}* \\
\left({ }^{*} \text { eykey-lo) }\right.\end{array}$ & $\begin{array}{c}\sqrt{ } \\
\left({ }^{*}-l o\right)\end{array}$ & & \\
\hline & twu-ta & $\begin{array}{c}* \\
\left({ }^{*} \text { eykey-lo) }\right.\end{array}$ & $\begin{array}{c}\sqrt{ } \\
\left({ }^{*}-l o\right)\end{array}$ & & \\
\hline & $\begin{array}{c}\text { neh-ta } \\
\text { (obtain) }\end{array}$ & $\begin{array}{c}* \\
\left({ }^{*} \text { eykey-lo) }\right.\end{array}$ & $\begin{array}{c}\sqrt{ } \\
\left({ }^{*}-l o\right)\end{array}$ & & \\
\hline & sayki-ta & $\begin{array}{c}* \\
\left({ }^{*} \text { eykey-lo }\right)\end{array}$ & $\begin{array}{c}\sqrt{ } \\
(*-l o)\end{array}$ & & \\
\hline & mol-ta & $\sqrt{ } 11)$ & $\begin{array}{c}\sqrt{ } \\
(\sqrt{ }-l o) \\
\end{array}$ & & \multirow{2}{*}{ send-type } \\
\hline & ponay-ta & $\begin{array}{c}\sqrt{ } \\
(\sqrt{ } \text { eykey-lo })\end{array}$ & $\begin{array}{l}\sqrt{ } \\
(\sqrt{ }-l o)\end{array}$ & & \\
\hline
\end{tabular}

10) According Mishani-Uval and Siloni (2016), it has to do with two cognitive principles Nunberg et al. (1994) proposed: (i) idioms tend not to include [+human] arguments in their fixed material due to the latter's reluctance to lose their animacy under figuration; (ii) open slots in idioms exhibit a tendency to require [+human] arguments. This explains why Fixed Goals are inanimates, while Open Goals are not subject to such requirement. 


\begin{tabular}{|c|c|c|c|c|c|}
\hline \multirow{2}{*}{ Idiom Type } & \multirow{2}{*}{ Verbs } & \multicolumn{2}{|c|}{$\begin{array}{l}\text { In Non-Idiomatic } \\
\text { Contexts }\end{array}$} & \multirow{2}{*}{ In Idioms } & \multirow{2}{*}{ Verb Type } \\
\hline & & $\begin{array}{c}\text {-eykey } \\
\text { (Animate) }\end{array}$ & $\begin{array}{c}-e y \\
\text { (Inanimate) } \\
\end{array}$ & & \\
\hline \multirow{15}{*}{$\begin{array}{l}\text { Fixed-Theme } \\
\text { (Open-Goal) }\end{array}$} & seywu-ta12) & $\begin{array}{c}* \\
\left({ }^{*} \text { eykey-lo }\right) \\
\end{array}$ & $\begin{array}{c}\sqrt{ } \\
(* l o) \\
\end{array}$ & $\begin{array}{l}\text { (In)Animate } \\
\text { Goals }\end{array}$ & \multirow{2}{*}{$\begin{array}{l}\text { Caused } \\
\text { Motion } \\
\text { verbs }\end{array}$} \\
\hline & $\begin{array}{c}\text { neh-ta } \\
\text { (let into) }\end{array}$ & $\begin{array}{c}* \\
* \\
\left({ }^{*} \text { eykey-lo }\right)\end{array}$ & $\begin{array}{c}\sqrt{ } \\
(\sqrt{ }-l o)\end{array}$ & Animate Goals & \\
\hline & kaha-ta & $\begin{array}{c}\sqrt{ } \\
\left({ }^{*} \text { eykey-lo) }\right.\end{array}$ & $\begin{array}{c}\sqrt{ } \\
\left({ }^{*}-l o\right)\end{array}$ & $\begin{array}{c}\text { Inanimate } \\
\text { Goals }\end{array}$ & \multirow{10}{*}{ send-type } \\
\hline & sso-ta & $\begin{array}{c}\sqrt{ } \\
(\sqrt{ } \text { eykey-lo })\end{array}$ & $\begin{array}{l}\sqrt{ } \\
(\sqrt{ }-l o)\end{array}$ & Animate Goals & \\
\hline & namil-ta & $\begin{array}{c}\sqrt{ } \\
(\sqrt{ } \text { eykey-lo }) \\
\end{array}$ & $\begin{array}{l}\sqrt{ } \\
(\sqrt{ }-l o)\end{array}$ & Animate Goals & \\
\hline & pachi-ta & $\begin{array}{c}\sqrt{ } \\
\left({ }^{*} \text { eykey-lo }\right)\end{array}$ & $\begin{array}{c}\sqrt{ } \\
(*-l o)\end{array}$ & $\begin{array}{l}\text { (In)Animate } \\
\text { Goals }\end{array}$ & \\
\hline & tolli-ta & $\begin{array}{c}\sqrt{ } \\
\left({ }^{*} \text { eykey-lo)}\right.\end{array}$ & $\begin{array}{c}\sqrt{ } \\
\left(*^{*}-l o\right)\end{array}$ & $\begin{array}{l}\text { (In)Animate } \\
\text { Goals }\end{array}$ & \\
\hline & kkien-ta & $\begin{array}{c}\sqrt{ } \\
\left({ }^{*} \text { eykey-lo }\right)\end{array}$ & $\begin{array}{c}\sqrt{ } \\
(\sqrt{ }-l o)\end{array}$ & $\begin{array}{l}\text { (In)Animate } \\
\text { Goals }\end{array}$ & \\
\hline & nay-ta & $\begin{array}{c}\sqrt{ } \\
\left({ }^{*} \text { eykey-lo }\right) \\
\end{array}$ & $\begin{array}{c}\sqrt{ } \\
(\sqrt{ }-l o) \\
\end{array}$ & $\begin{array}{l}\text { (In)Animate } \\
\text { Goals }\end{array}$ & \\
\hline & $\begin{array}{l}\text { noh-ta } \\
\text { (stick) }\end{array}$ & $\sqrt{ } 13)$ & $\begin{array}{c}\sqrt{ } \\
\left({ }^{*}-l o\right)\end{array}$ & Animate Goals & \\
\hline & tenci-ta & $\begin{array}{c}\sqrt{ } \\
(\sqrt{ } \text { eykey-lo }) \\
\end{array}$ & $\begin{array}{c}\sqrt{ } \\
(\sqrt{ }-l o) \\
\end{array}$ & $\begin{array}{c}\text { Inanimate } \\
\text { Goals }\end{array}$ & \\
\hline & tay-ta & $\begin{array}{c}\sqrt{ } \\
(\sqrt{ } \text { eykey-lo })\end{array}$ & $\begin{array}{c}\sqrt{ } \\
(\sqrt{ }-l o)\end{array}$ & $\begin{array}{l}\text { Inanimate } \\
\text { Goals }\end{array}$ & \\
\hline & meki-ta & $\begin{array}{c}\sqrt{ } \\
\left({ }^{*} \text { eykey-lo }\right)\end{array}$ & $\begin{array}{c}* \\
(*-l o)\end{array}$ & Animate Goals & \multirow{3}{*}{$\begin{array}{l}\text { Caused } \\
\text { Possession/ } \\
\text { give-type }\end{array}$} \\
\hline & cwu-ta & $\begin{array}{c}\sqrt{ } \\
\left({ }^{*} \text { eykey-lo }\right)\end{array}$ & $\begin{array}{c}* \\
\left({ }^{*}-l o\right)\end{array}$ & Animate Goals & \\
\hline & pal-ta & $\begin{array}{c}\sqrt{ } \\
\left({ }^{*} \text { eykey-lo }\right)\end{array}$ & $\begin{array}{c}* \\
(*-10)\end{array}$ & $\begin{array}{l}\text { (In)Animate } \\
\text { Goals }\end{array}$ & \\
\hline \multirow{5}{*}{ Full Idioms } & tal-ta & $\begin{array}{c}* \\
\left({ }^{*} \text { eykey-lo) }\right.\end{array}$ & $\begin{array}{c}\sqrt{ } \\
\left({ }^{*}-l o\right)\end{array}$ & \multirow{5}{*}{$\begin{array}{c}\text { Fixed-Goals \& } \\
\text { - Fixed Themes: } \\
\text { Only } \\
\text { Inanimate } \\
\text { Goals }\end{array}$} & \multirow{3}{*}{$\begin{array}{c}\text { Caused } \\
\text { Motion verbs }\end{array}$} \\
\hline & pwum-ta & $\begin{array}{c}* \\
\left({ }^{*} \text { eykey-lo }\right)\end{array}$ & $\begin{array}{c}\sqrt{ } \\
(*-10)\end{array}$ & & \\
\hline & chi-ta & $\begin{array}{c}* \\
\left({ }^{*} \text { eykey-lo }\right)\end{array}$ & $\begin{array}{l}\sqrt{ } \\
(\sqrt{ }-l o)\end{array}$ & & \\
\hline & pak-ta & $\sqrt{ } 14)$ & $\begin{array}{c}\sqrt{ } \\
\left({ }^{*}-l o\right)\end{array}$ & & \multirow{2}{*}{ send-type15) } \\
\hline & pwus-ta & $\begin{array}{c}\sqrt{ } \\
\left({ }^{*} \text { eykey-lo }\right)\end{array}$ & $\begin{array}{c}\sqrt{ } \\
\left(*^{*}-l o\right)\end{array}$ & & \\
\hline
\end{tabular}

11) koyangi-lul aitul-eykey(-lo) mol-ta 'cat-Acc kids-Dat(-LO) drive' 


\subsection{Interim Data Summary}

The relevant data from three languages are summarized in (27) and (28). We can see that Korean patterns largely with Hebrew and English to a certain extent in terms of verb types involved in ditransitive idioms, and that it is subject to Verb-Sensitivity too: Give-type verbs do not occur when the Goal argument is a fixed part of idioms; Fixed-Goal (Open-Theme) idioms and Full idioms only occur with send-type verbs or Caused Motion-only verbs ${ }^{16)}$ that take Spatial Goals. However, three languages are not exactly the same. Korean is more liberal in terms of available verb types in Fixed-Theme (Open-Goal) idioms, contrary to Hwang's (2015) claim that only give-type verbs appear in Fixed-Theme idioms. To recap, three languages behave the same way regarding Fixed-Goal idioms (be it partial or full), but Korean is different from the others for Open-Goal (Fixed-Theme) idioms with respect to the involved verb types. It allows wider range of verbs.

12) It is possible to have animate Goals when abstract Themes are used. Other verbs may exhibit similar behavior.

13) -eykey cwusa-lul noh-ta '-Dat shot/injection-Acc stick'

14) Yeswu-eykey mos-ul pak-ta 'Jesus-Dat nail-Acc hammer'

15) There seems to be an exception to the verb type generalization for Full idioms such as 'mok-ey him-ul cwu-ta (neck-Dat strength/power-Acc give),' and 'ekkey-ey him-ul cwu-ta (shoulder-Dat strength/power-Acc give)', both of which means 'to be arrogant' or 'put on airs,' since the verb cwu-ta ('give') is used. In these idioms, the verb cwu-ta does not have a sense of transfer and has a meaning such as kaha-ta (add, put on), which is a send-type verb. Its meaning is different from cwu-ta in '-eykey kwi-lul cwu-ta (ear-Acc give),' which means 'to eavesdrop on x.' I will take the two examples as apparent exceptions.

16) A reviewer notes that Caused Motion verbs appear in all three subtypes of idioms, and asks whether there is any difference among these Caused Motion verbs in terms of in which subtype they appear. I tried to see whether there is any morphological, syntactic, or lexical semantic differences, but I have not been able to find any meaningful difference. It might be that some Caused Motion verbs in Full idioms somehow look like verbs of putting in a spatial configuration; that some Caused Motion verbs in Fixed-Goal (Open-Theme) idioms seem to be verbs of continuous causation of accompanied motion in some manner. But, verbs of putting occur across Fixed-Goal (Open-Theme) and Fixed-Theme (Open-Goal) idioms. In Hebrew, too, verbs of inherently direct motion (e.g., Hebrew verb corresponding to return) occur in both Full and Fixed-Goal (Open-Theme) idioms. Certainly, this question deserves further study, but it seems like a question that calls for lengthy discussion on lexical semantics/syntax interface of Korean verbs. Due to time limitation, I cannot provide a meaningful discussion in the current paper. I leave this for future research. 


\section{(27) Korean}

a. PDC:

\begin{tabular}{|c|c|c|c|}
\hline Idiom Type & $\begin{array}{c}{\left[\text { Dat }_{\text {Goal- }} \text { Acc }_{\text {Theme }}\right]} \\
(=\mathrm{PDC})\end{array}$ & $\begin{array}{c}{\left[\mathrm{Acc}_{\text {Theme- }}-\mathrm{Dat}\right.} \\
(=\mathrm{PDCa}) \\
\text { GD })\end{array}$ & Verbal Head \\
\hline $\begin{array}{l}\text { Fixed-Goal } \\
\text { (Open-Theme) }\end{array}$ & * & $\sqrt{ }$ & $\begin{array}{l}\text { Caused Motion; } \\
\text { or } \\
\text { send-type verbs } \\
\text { (with Spatial } \\
\text { Goal) }\end{array}$ \\
\hline $\begin{array}{l}\text { Fixed-Theme } \\
\text { (Open-Goal) }\end{array}$ & $\sqrt{ }$ & * & $\begin{array}{c}\text { give-type verbs } \\
\text { (with Recipient } \\
\text { Goals); } \\
\text { send-type verbs or } \\
\text { Caused Motion } \\
\text { verbs (with Spatial } \\
\text { Goals) }\end{array}$ \\
\hline $\begin{array}{c}\text { Full } \\
\text { (Fixed-Goal, } \\
\text { Fixed-Theme) }\end{array}$ & $\sqrt{ }$ & * & $\begin{array}{l}\text { Caused Motion; } \\
\text { or } \\
\text { send-type verbs } \\
\text { (with Spatial } \\
\text { Goal) }\end{array}$ \\
\hline
\end{tabular}

b. DOC:

\begin{tabular}{|c|c|c|c|}
\hline Idiom Type & $\begin{array}{c}{\left[\mathrm{Acc}_{\text {Goal }}-\mathrm{Acc}_{\text {Theme }}\right]} \\
(=\mathrm{DOC})\end{array}$ & $\begin{array}{c}{\left[\mathrm{Acc}_{\text {Theme }}-\mathrm{Acc}_{\mathrm{Goal}}\right]} \\
(=\mathrm{DOC})\end{array}$ & Verbal Head \\
\hline $\begin{array}{c}\text { Fixed-Goal } \\
\text { (Open-Theme) }\end{array}$ & * & * & N/A \\
\hline $\begin{array}{l}\text { Fixed-Theme } \\
\text { (Open-Goal) }\end{array}$ & $\sqrt{ }$ & * & $\begin{array}{l}\text { give-type verbs } \\
\text { with (Recipient } \\
\text { Goals); or } \\
\text { send-type verbs or } \\
\text { Caused Motion } \\
\text { verbs (with Spatial } \\
\text { Goals)17)18) }\end{array}$ \\
\hline $\begin{array}{c}\text { Full } \\
\text { (Fixed-Goal, } \\
\text { Fixed-Theme) }\end{array}$ & * & * & N/A \\
\hline
\end{tabular}

17) These are verbs listed in (8a): neh-ta, kaha-ta, kkien-ta, noh-ta, meki-ta, and cwu-ta. Not all verbs in Fixed-Theme (Open-Goal) idiom section in (26) participate in idiom formation in the Acc-Acc pattern.

18) A reviewer mentions that Korean send-type verbs do not appear at all in the DOC (i.e. Acc-Acc pattern). It is right in non-idiomatic contexts. However, in idioms, some send-type verbs and Caused Motion-only verbs may occur in the Acc-Acc pattern in addition to the Dat-Acc pattern. For example, although the verbs neh-ta and noh-ta do not appear in the Acc-Acc pattern in non-idioms (e.g., cwumeni-ey/*-lul ton-ul neh-ta 'pocket-Dat/*-Acc money-Acc put.into', pal-ey/*-ul cwusa-lul noh-ta 'arm-Dat/ -*Acc shot-Acc stick/put.on/apply.'), they allow the Acc-Acc idiom formation (e.g., -eykey/-lul palam-ul neh-ta 'instigate', -eykey/-lul (il)chim-ul noh-ta 'scold, warn') (cf. K 
(28) Hebrew and English (repeated from 19)

\begin{tabular}{|c|c|c|c|}
\hline Idiom Type & $\begin{array}{l}\text { TH-GL order } \\
\text { (PDC) }\end{array}$ & $\begin{array}{l}\text { GL-TH order } \\
\text { (DOC) }\end{array}$ & Verbal Head \\
\hline $\begin{array}{l}\text { Fixed-Goal } \\
\text { (Open-Theme) }\end{array}$ & $\sqrt{ }$ & */?? & $\begin{array}{l}\text { Caused Motion; or } \\
\text { send-type verbs } \\
\text { (with Spatial Goal) }\end{array}$ \\
\hline $\begin{array}{l}\text { Fixed-Theme } \\
\text { (Open-Goal) }\end{array}$ & $\sqrt{ }$ & $\sqrt{ }$ & $\begin{array}{c}\text { give-type verbs; or } \\
\text { send-type verbs } \\
\text { (with Recipient Goal) }\end{array}$ \\
\hline $\begin{array}{c}\text { Full } \\
\text { (Hebrew) }\end{array}$ & $\sqrt{ }$ & */?? & $\begin{array}{l}\text { Caused Motion; or } \\
\text { send-type verbs } \\
\text { (with Spatial Goal) }\end{array}$ \\
\hline
\end{tabular}

\section{Previous Approaches to Idiom Formation}

There are two main approaches to the distribution of ditransitive idioms: Constituency-based approaches and Selection-based approaches. Both are structure-based approaches. Mishani-Uval and Siloni (2016) argue that none of the analyses in these approaches are sufficient to explain Hebrew facts. They go for Rappaport Hovav and Levin's (2008) Verb-Sensitivity approach, which is not structure-based. Hwang (2015) criticizes L Kim's (2015) analysis of Korean ditransitive idioms that is built on selection-based approaches and argues for Verb-Sensitivity approach. She argues that structure-based selection approaches cannot capture Korean idiom facts. In this section, I will summarize and review previous approaches, which will be followed by a new analysis in section 5 .

\subsection{Constituency-Based Approaches}

Larson (1988) assumes that idioms must form continuous constituents when they are inserted into syntactic structure. Although his approach fails to predict the absence of Fixed-Goal (Open-Theme) idioms in the DOC and the presence of Fixed-Theme (Open-Goal) idioms due to the ditransitive structures he posits, as already criticized in the literature,19)

M Kim 2015, Hwang 2015 for data).

19) The previous literature has already noted that Larson's VP shell analysis (deriving 
the constituency hypothesis that (rigid) idioms are interpretable only when reflecting the base structure of arguments has been standard in the literature.

Harley (2002) is a more recent proposal based on the view that idioms are underlyingly constituents. Harley proposes the following small clause structures for the PDC (29a) and the DOC (29b), which are base-generated independently from each other. In her approach, the PDC is associated with Caused Motion meaning, and the DOC is associated with Caused Possession meaning.
(29)
a. PDC: [vp Agent cause [ $\mathrm{PP}(=\mathrm{SC})$ Theme [ $\mathrm{P}_{\mathrm{Loc}}$ Goal]]] b. DOC: [vp Agent cause [ ${ }_{\mathrm{PP}(=\mathrm{SC})}$ Goal [ $\mathrm{P}_{\mathrm{HAVE}}$ Theme]]]

It is pointed out - Breuning (2010) for English and Misahni-Uval and Siloni (2016) for Hebrew - that Harley's approach fails to predict the existence of Fixed-Theme (Open-Goal) idioms in the PDC, because in the PDC structure in (29a), the Theme does not form a constituent with $\mathrm{P}_{\mathrm{Loc}}$.

Mishani-Uval and Siloni (2016) strongly argue against any kind of structural constituency approach and claim that idioms do not have to be continuous constituents (at some stage of derivation), as the PDC (i.e. V-Theme-Goal order) has both Fixed-Goal (Open-Theme) and Fixed-Theme (Open-Goal) idioms but there is no unique structure which can yield both facts in constituency-based approaches.

the DOC from the PDC) does not correctly predict the inventory of possible ditransitive idioms.

(i) a. PDC: [vp Agent $v_{i}$ [vp Theme [t to Goal]]]

b. DOC: [vp Agent $v_{i}$ [vp Goal $k_{k}\left[\left[t_{i}\right.\right.$ to $\left.t_{k}\right]$ Theme]]]

In Larson's PDC structures (ia), the PP Goal always forms an immediate constituent with the verb, so it fails to predict the presence of Fixed-Theme (Open-Goal) idioms in the PDC. As pointed out by Harley (2002), it also fails to predict the absence of Fixed-Goal (Open-Theme) idioms in the DOC, because when the DOC is derived from the PDC, the movement of the Goal results in forming a constituent with the verb. 


\subsection{Selection-Based Approaches}

Recently, Bruening (2010:532) proposed a selection-based approach, leaning heavily upon O'Grady's (1998) Continuity Constraint approach. Specifically, he proposes the following: (i) the Principle of Idiomatic Interpretation and (ii) Constraint on Idiomatic Interpretation.

(30) The Principle of Idiomatic Interpretation

$\mathrm{X}$ and $\mathrm{Y}$ may be interpreted idiomatically only if $\mathrm{X}$ selects $\mathrm{Y}$.

(31) Constraint on Idiomatic Interpretation

If $\mathrm{X}$ selects a lexical category $\mathrm{Y}$, and $\mathrm{X}$ and $\mathrm{Y}$ are interpreted idiomatically, all of the selected arguments of $\mathrm{Y}$ must be interpreted as part of the idiom that includes $\mathrm{X}$ and $\mathrm{Y}$.

(Lexical categories are $\mathrm{V}, \mathrm{N}, \mathrm{A}$, and Adv.)

As noted earlier, Bruening proposes the following structures for the PDC and the DOC.

(32) a. PDC in English and Hebrew

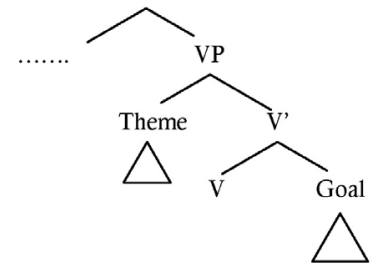

b. DOC in English and Hebrew

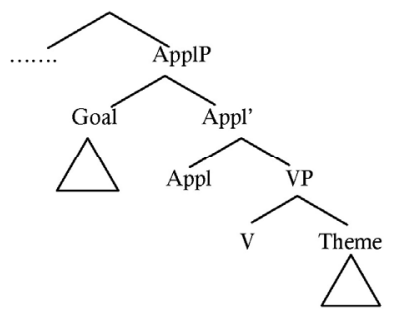


Bruening's approach can explain that Fixed-Goal (Open-Theme) idioms are possible in the PDC (32a), as V selects the Goal argument (specifically, $\mathrm{V}$ selects $\mathrm{P}$ and $\mathrm{P}$ selects the DP inside the Goal). It also predicts that such idioms are not available in the DOC (32b), because the idioms would have to have the Goal, Appl, and V be interpreted idiomatically, excluding the Theme; but Appl selects the Goal and V, and since V is a lexical category, the Theme must also be part of the idiom, according to (31). So, it is not possible to exclude the Theme from the idiom and to form Fixed-Goal idioms with Open-Theme in the DOC. Breuning's approach can also account for the existence of Fixed-Theme (Open-Goal) idioms in both the PDC (32a) and the DOC (32b), as in both structures, V selects the Theme and forms an idiomatic constituent with it.

However, Mishani-Uval and Siloni (2016) point out that Bruening's idiom-as-selection proposal fails regarding Full idioms (with Fixed-Goal and Fixed-Theme), as the proposal predicts that both the PDC and the DOC can allow Full idioms, contrary to fact. Full idioms are available only in the PDC in all three languages. The nonexistence of Full idioms in the DOC is not accounted for. To explain the lack of Full idioms in the DOC, L Kim (2015), whose analysis is built on Bruening's approach, suggests that Appl cannot participate in idiom formation in Korean, i.e. Appl is beyond the domain for idiomatic reading. ${ }^{20)}$ According to Mishani-Uval and Siloni (2016), L Kim's suggestion can explain the fact that the Goal can never belong to fixed part of idioms in the DOC; But they criticize that how selection works in general seems ad hoc, because in order for the Goal of the DOC to participate in the idiom, its selector Appl must also be part of the idiom, but for the Theme to be fixed part of the idiom with $\mathrm{V}$ in the DOC, Appl does not have to be part of the idiom even though it selects V. K-M Kim (2015) also criticizes idiom-as-selection approach because it does not rule out the specifiers of functional heads (i.e. the Goal in the DOC) in a principled manner, and they can be included in the idioms in unpredictable ways. I would like to add another problem for Bruening-type selection approach. An Appl head

20) Bruening (2010) argues that Appl is part of the idiom for Fixed-Theme idioms such as give $X$ the boot, i.e. Appl-V-Theme forms an idiom. 
introduces an applied argument with Possessor/Recipient role (e.g. lend $x$ an earllend an ear to $x$ ). According to Levin, idioms lend $x$ an ear and give $x$ a creep both are examples of Fixed-Theme (Open-Goal) idioms, but Bruening argues that only the $\mathrm{V}+\mathrm{Theme}$ forms an idiom for lend $x$ an ear (which alternates with lend an ear to $x$ ), and give $x$ a creep (which, he incorrectly claims not to alternate with give a creep to $x$ ) involves Appl+V+Theme as an idiom. When the Goal argument and the Appl head in both idioms are associated with the same Recipient/Possessor semantics, it appears ad hoc to claim that Appl is part of idiom in only one case, and not in the other. In other words, the idea that sometimes Appl is part of the idiom and sometimes not in the Fixed-Theme (Open-Goal) idioms of the DOC seems stipulative. In conclusion, there is something stipulative and ad hoc in how selection is implemented in Bruening's selection-based approaches.

\section{3. (Non-Structural) Verb Sensitivity Approaches}

\subsubsection{Mishani-Uval and Siloni (2016)}

Based on their criticisms against both constituency-based approaches and selection-based approaches to idiom formation (summarized in 4.1 and 4.2), Mishani-Uval and Siloni (2016) conclude that these structure-based proposals fail to account for the pattern of ditransitive idioms in Hebrew. They show that idioms reflect properties of their non-idiomatic literal counterparts in terms of being verb-sensitive in their distribution. And, they argue that idioms do not have to be continuous structural constituents, based on the lack of a unique structure which can yield both Fixed-Goal (Open-Theme) and Fixed-Theme (Open-Goal) idioms in the PDC. The word order (Theme-Goal or Goal-Theme) is correlated with argument structure types (PDC or DOC) in Hebrew and English, and idioms are not subject to linear adjacency constraint between $\mathrm{V}$ and fixed argument either, as illustrated in (33), i.e. the word order constraint in idioms is not a linear adjacency constraint, but an (argument) structure-related one. 
(33) a. Fixed-Goal (Open-Theme) idioms: [V]-Theme-[Goal] (PDC)

b. Fixed-Theme (Open-Goal) idioms: [V-Theme]-Goal (PDC) or [V]-Goal-[Theme] (DOC)

c. Full idioms (with Fixed-Goal and Fixed-Theme): [V-Theme-Goal] (PDC)

\subsubsection{Hwang (2015)}

As we saw in (1a) and (2a), Korean, being a scrambling language, allows relatively free word order among arguments. However, Hwang (2015) shows that idiomatic interpretation is determined by word order rigidity between the Theme and the Goal with respect to a verb. In Fixed-Goal (Open-Theme) idioms, the Goal must follow the Theme and be adjacent to the Verb (i.e. $\sqrt{ }$ Theme-[Goal-V], *[Goal]-Theme-[V]), as the contrast between $(34 a, b)$ and $\left(34 a^{\prime}, b^{\prime}\right)$ shows. The idiomatic reading is available only in the Theme-Goal order. (The data in (34a,a') and $\left(35 \mathrm{a}, \mathrm{a}^{\prime}\right)$ are taken from Hwang 2015 and the others are composed by the author). The data in (34-36) show that the word order is crucial for idiomatic interpretations to obtain, i.e. ditransitive idiom formation is sensitive to the word order between $\mathrm{V}$ and internal arguments. According to Hwang (2015), idiomatic reading cannot be guaranteed unless the word order is constrained. I agree with Hwang on this point.21)

(34) (Sanghwang-ul cengli-ha-ki wihay)

(situation-Acc complete-do-Nmz in.order),

a. ku-nun ku salam-ul sonakwi-ey cwi-eya-hay-ssta. (= 3b: Open-Theme $>$ Fixed-Goal) he-Top that person-Acc hand-Dat grasp-must-Pst-Dec.

Literal: 'He must grasp that person.'

Idiomatic: 'He must have power over that person.' (available)

a'. ku-nun sonakwi-ey ku salam-ul cwi-eya-hay-ssta. he-Top hand-Dat that person-Acc grasp-must-Pst-Dec. (Fixed-Goal > Open-Theme) Literal: 'He must grasp that person.'

Idiomatic: 'He must have power over that person.' (not available)

21) L Kim (2015) also acknowledges this word order constraint, but she suggests that the constraint is not as strong a constraint to define a general pattern of idioms in Korean and that it is only a strong preference at surface structure. Although the degree might differ from one idiom to another, I think that the constraint is very strong and reversing the two internal arguments in general leads to the loss of idiomatic interpretation. 
b. Mary-nun John-eykey ton-ul mek-i-ess-ta.

Mary-Top John-Dat money-Acc eat-Caus-Pst-Dec

Literal: 'Mary caused John to eat money.'

Idiomatic: 'Mary bribed John.' (available)

b'. Mary-nun ton-ul John-eykey mek-i-ess-ta.

Mary-Top money-Acc John-Dat eat-Caus-Pst-Dec

Literal: 'Mary caused John to eat money.'

Idiomatic: 'Mary bribed John.' (not available)

(35) a. Sensayngnim-i aitul-eykey chim-ul noh-ass-ta

teacher-Nom kids-Dat needle-Acc stick/put.onto-Pst-Dec

Literal: 'The teacher stuck/put/gave a needle at the kids.

Idiomatic: 'The teacher scolded/warned the kids (to be quiet).' (available)

a'. Sensayngnim-i chim-ul aitul-eykey noh-ass-ta

teacher-Nom needle-Acc kids-Dat stick/put.onto-Pst-Dec

Literal: 'The teacher stuck/put/gave a needle at the kids.'

Idiomatic: 'The teacher scolded/warned the kids (to be quiet).' (not available)

b. Inho-ka Mary-eykey tung-ul toli-ess-ta.

Inho-Nom Mary-Dat back-Acc turn-Pst-Dec.

Literal: 'Inho turned his back to Mary.'

Idiomatic: 'Inho betrayed/parted from Mary.' (available)

b'. Inho-ka tung-ul Mary-eykey toli-ess-ta.

Inho-Nom back-Acc Mary-Dat turn-Pst-Dec.

Literal: 'Inho turned his back to Mary.'

Idiomatic: 'Inho betrayed/parted from Mary.' (not available)

(36) a. Swuni-ka kasum-ey kal-ul pum-ess-ta

Suni-Nom chest-Dat knife-Acc bear-Pst-Dec

Literal: 'Suni bore a knife in the chest.'

Idiomatic: 'Suni cherished resentment.' (available)

a'. Swuni-ka kal-ul kasum-ey pum-ess-ta

Suni-Top knife-Acc chest-Dat bear-Pst-Dec

Literal: 'Suni bore a knife in the chest.'

Idiomatic: 'Suni cherished resentment.' (not available)

b. Mina-ka pwul-ey kilum-ul pwu-ess-ta

Mina-Nom fire-Dat oil-Acc pour-Pst-Dec

Literal: 'Mina poured oil onto the fire.'

Idiomatic: 'Mina worsened the situation.' (available) 


\section{b'. Mina-ka kilum-ul pwul-ey pwu-ess-ta \\ Mina-Nom oil-Acc fire-Dat pour-Pst-Dec \\ Literal: 'Mina poured oil onto the fire.' \\ Idiomatic: 'Mina worsened the situation.' (not available)}

Hwang (2015), in fact, claims that Korean ditransitive idiom formation cannot be accounted for in structural terms, arguing against syntactic accounts such as L Kim (2015). She argues that Fixed-Goal (Open-Theme) idioms have send-type verbal heads and require the adjacency between the Goal and V (i.e. Theme [Goal-V]) ${ }^{22)}$; and that Fixed-Theme (Open-Goal) idioms have give-type verbal heads and require the adjacency between the Theme and V (i.e. Goal [Theme V]). I showed in section 3.2 that Hwang is wrong in claiming that Fixed-Theme (Open-Goal) idioms occur only with give-type verbs. But, she is correct to claim that such idioms should occur in the Goal-Theme-V order, as summarized in (37).

(37) Korean (partially repeated from 27)

a. PDC:

\begin{tabular}{|c|c|c|c|}
\hline Idiom Type & $\begin{array}{c}{\left[\mathrm{Dat}_{\text {Goal }}-\mathrm{Acc}_{\text {Theme }}\right]} \\
\text { (=PDC) }\end{array}$ & $\begin{array}{c}{\left[\text { Acc }_{\text {Theme }}-\mathrm{Dat}_{\text {Goal }}\right]} \\
\text { (=PDC) }\end{array}$ & Verbal Head \\
\hline $\begin{array}{l}\text { Fixed-Goal } \\
\text { (Open-Theme) }\end{array}$ & * & $\begin{array}{c}\sqrt{ } \\
\text { (Theme-Goal-V) }\end{array}$ & $\begin{array}{l}\text { Caused Motion; or } \\
\text { send-type verbs } \\
\text { (with Spatial Goal) }\end{array}$ \\
\hline $\begin{array}{l}\text { Fixed-Theme } \\
\text { (Open-Goal) }\end{array}$ & $\begin{array}{c}\sqrt{ } \\
\text { (Goal-Theme-V) }\end{array}$ & * & $\begin{array}{l}\text { give-type verbs (with } \\
\text { Recipient Goals); } \\
\text { send-type verbs or } \\
\text { Caused Motion verbs } \\
\text { (with Spatial Goals) }\end{array}$ \\
\hline $\begin{array}{l}\text { Full (Fixed-Goal, } \\
\text { Fixed-Theme) }\end{array}$ & $\begin{array}{c}\sqrt{ } \\
\text { (Goal-Theme-V) }\end{array}$ & * & $\begin{array}{l}\text { Caused Motion; or } \\
\text { send-type verbs } \\
\text { (with Spatial Goal) }\end{array}$ \\
\hline
\end{tabular}

22) Hwang (2015:449) mentions Fixed-Theme (Open-Goal) idioms like '-ey mom-ul tenci-ta (-Dat body-Acc throw) (i.e. devote oneself to $\mathrm{x}$ )' and '-eykey naksi-lul tenci-ta (-Dat bait-Acc throw) (i.e. deceive x)', which occur in the Goal-Theme-V order. Since the verb 'tenci-ta' belongs to the send-type, it is expected to occur in the Theme-Goal-V order for her, contrary to fact. Hwang (2015) leaves this as a remaining problem for her analysis. But, I showed in 3.2 that send-type verbs can occur in Fixed-Theme (Open-Goal) idioms (i.e. in the Goal-Theme-V) with either animate or inanimate Goals. 
b. DOC:

\begin{tabular}{cccc}
\hline Idiom Type & $\begin{array}{c}{\left[\mathrm{Acc}_{\text {Goal-Acc }}(\mathrm{Aheme})\right.} \\
(=\mathrm{DOC})\end{array}$ & $\begin{array}{c}{\left[\mathrm{Acc}_{\text {Theme }}-\mathrm{Acc}_{\text {Goal }}\right]} \\
(=\mathrm{DOC})\end{array}$ & Verbal Head \\
\hline $\begin{array}{c}\text { Fixed-Goal } \\
\text { (Open-Theme })\end{array}$ & $*$ & $*$ & N/A \\
\hline $\begin{array}{c}\text { Fixed-Theme } \\
\text { (Open-Goal) }\end{array}$ & $\begin{array}{c}\text { (Goal-Theme-V) } \\
\text { Full }\end{array}$ & $*$ & $\begin{array}{c}\text { give-type verbs with } \\
\text { (Recipient Goals); } \\
\text { or send-type verbs or } \\
\text { Caused Motion verbs } \\
\text { (with Spatial Goals) }\end{array}$ \\
$\begin{array}{c}\text { (Fixed-Goal, } \\
\text { Fixed-Theme) }\end{array}$ & $*$ & $*$ & N/A \\
\hline
\end{tabular}

(38) Hebrew and English (repeated from 19 and 28)

\begin{tabular}{cccc}
\hline Idiom Type & $\begin{array}{c}\text { TH-GL order } \\
\text { (PDC) }\end{array}$ & $\begin{array}{c}\text { GL-TH order } \\
\text { (DOC) }\end{array}$ & Verbal Head \\
\hline $\begin{array}{c}\text { Fixed-Goal } \\
\text { (Open-Theme) }\end{array}$ & $\sqrt{ }$ & $* / ? ?$ & $\begin{array}{c}\text { Caused Motion; or } \\
\text { send-type verbs } \\
\text { (with Spatial Goal) }\end{array}$ \\
\hline $\begin{array}{c}\text { Fixed-Theme } \\
\text { (Open-Goal) }\end{array}$ & $\sqrt{ }$ & $\sqrt{ }$ & $\begin{array}{c}\text { give-type verbs; or } \\
\text { send-type verbs } \\
\text { (with Recipient Goal) }\end{array}$ \\
\hline $\begin{array}{c}\text { Full } \\
\text { (English??) }\end{array}$ & $\sqrt{ }$ & $* / ? ?$ & $\begin{array}{c}\text { Caused Motion; or } \\
\text { send-type verbs } \\
\text { (with Spatial Goal) }\end{array}$ \\
\hline
\end{tabular}

\section{A Constituency-Based Analysis of Idioms in Verb-Sensitivity Approach}

\subsection{English and Hebrew}

Hallman (2015) endorses Rappaport Hovav and Levin's Verb-Sensitivity approach, and interprets it in structural terms. He does not discuss subtypes of English ditransitive idioms to the full extent. In this section, I will show that his approach can explain all Hebrew and English facts we 
have observed.

Hallman's main claim is that there are two subtypes of the PDC in English: (i) Base-generated PDCs (with Caused Motion semantics) and (ii) Derived PDCs (with Caused Possession semantics). For give-type verbs, the PDC is always derived from the DOC, and a Caused Possession meaning is conveyed in both argument structures. As for send-type verbs, the PDC is either derived from the DOC (Caused Possession meaning) or base-generated as such (Caused Motion meaning). Naturally, there are two possible structures for the PDC with send-type verbs. Although Hallman does not assume applicative structures for the DOC, the structure for give-type verbs still has an additional functional layer $v \mathrm{P}$ hosting the Goal argument (which is similar to ApplP), as in (39a). The PDC can be derived from the DOC via internal passivization, as in (39b): the demotion of the Goal argument (to rightward V' adjunct position) results in the reversed word order and the appearance of the preposition to. Send-type verbs (with animate Goals) and give-type verbs appear in this structure. The structure in (39c) is for the base-generated PDC that occurs with send-type verbs that are used with inanimate Spatial Goals.

(39) a. DOC

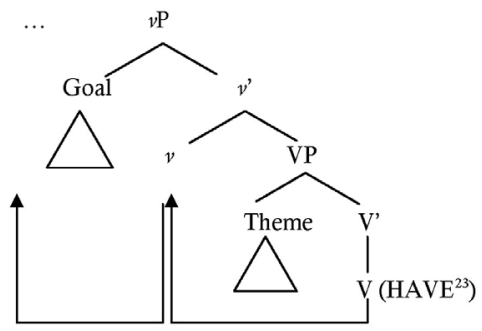

23) In lexical decomposition approaches to ditransitives (e.g., Harley 2002 and others), give-type verbs are assumed to have an abstract possessive predicate HAVE (POSSESSION) component. The lexical core of the possession structure in the give-type verbs is the have relation, and it has been noted that give and have share many syntactic and semantic similarities. Hallman (2015) suggests that Big-V HAVE in (39a) corresponds to what Harley calls $\mathrm{P}_{\mathrm{HAVE}}$, and the English verb have is the spell-out of a complex head formed by verb movement. In recent Applicative Hypothesis of the Double Object Construction, the possessor Goal argument is argued to be outside the lexical verb's theta domain as an extra argument, i.e. it is treated as a kind of external argument in the specifier position of high applicative phrases (cf. Marantz 1993, Bruening 2001, Miyagawa and Tsujioka 2004, Jeong 2007, Bruening 2010, L Kim 2015). In this line of approaches, one of the important 


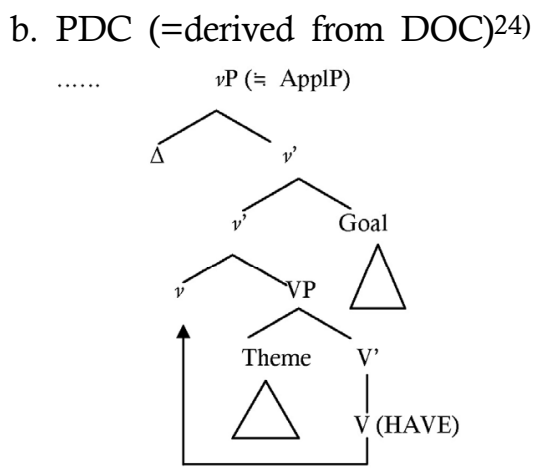

c. PDC (=base-generated)

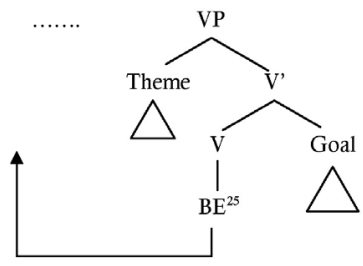

differences between the DOC and the PDC is that in the DOC the Goal and the Theme are arguments of different heads, but in the PDC, they are arguments of the same head. Specifically, the Appl head is responsible for the meaning of possession, the meaning which is absent in the PDC. Different properties of the Goal argument in the DOC vs. the PDC are attributed to this structural distinction, which also reflects semantic differences as well. See Bruening (2001, 2010), Cuervo (2003), L Kim (2015), and Harley and Miyagawa (2017) for further discussion. Bruening (2010), in particular, presents a very detailed semantic computation, which incorporates HAVE component of Harley in an applicative analysis of the DOC.

24) A reviewer asks about the motivation for V-to- $v$ movement. In $(39 \mathrm{a}, \mathrm{b})$, the little $v$ corresponds to a high applicative head in the Applicative Hypothesis for the DOC, and there is another higher little $v$ /VOICE head above, which is assumed to encode a causative meaning. The V-r(Appl)-r(Voice) movement can be analyzed as a complex predicate formation, by which the complex head with $v$ /VOICE, $v /$ Appl, and V-HAVE comes to be spelled-out as lexical verbs including give (cf. Distributed Morphology theory of lexical insertion). As the Theme's theta role assignment is done in-situ with V-HAVE, the verb movement does not affect theta properties of the Theme, although the movement affects the theta role assignment of the Goal. See Bruening (2010) for detailed syntactic and semantic derivation in this kind of approach.

25) The abstract predicate V-BE is an existence predicate. This captures the locative meaning of the PDC (i.e. X cause Y to BE AT Z). Unlike the DOC, both the Goal and the Theme arguments are merged in the domain of this V-BE. A reviewer asks whether the structural difference fits general intuition. This question concerns the recent debate between Harley's symmetric theory for the DOC/PDC and Bruening's asymmetric theory for the DOC/PDC. See L Kim (2015) for a nice summary of the controversy and arguments for the latter from both Korean and English. Arguments include facts from QR, nominalization, depictive modification, etc. 
Now, we can explain ditransitive idiom patterns for Hebrew and English, summarized in (38), in constituency-based approach. This account was suggested by Hallman (2015) for English, although he does not discuss all subtypes of English idioms. Here, I suggest that it can be extended to Hebrew as well, as it shows the same pattern as English. First, Fixed-Goal (Open-Theme) idioms with verbs taking Spatial Goals would have the structure (39c). In this kind of structure, the Goal argument forms a constituent with the verbal head, yielding Fixed-Goal (Open-Theme) idioms. Secondly, Full idioms (which Hallman does not discuss) would also have a structure like (39c), where a verb forms a constituent with both the Theme and the Goal. Lastly, in the case of Fixed-Theme (Open-Goal) idioms, they, in general, show alternation between the PDC and the DOC, and always take animate Recipient Goals. So, the structure for the DOC would be (39a), and the PDC would have a derived structure in (39b). In both structures, V forms a constituent with the Theme.

Bruening's selection approach can also explain the above facts. However, there is a crucial problem for this approach, as this approach fails to explain the non-existence of Fixed-Theme (Open-Goal) idioms that occur with verbs taking Spatial Goals. In other words, now that we have established that all Fixed-Theme (Open-Goal) idioms actually occur in either DOC (39a) or derived PDC (39b), i.e. idiom formation is verb-sensitive, there is no Fixed-Theme (Open-Goal) idioms occurring in the base-generated PDC (39c); However, selection-based approach incorrectly predicts that such idioms are possible, because $\mathrm{V}$ selects the Theme in (39c).

Although Mishani-Uval and Siloni (2016) argue against any constituency-based analysis, we can see that once we adopt Hallman-style structural verb-sensitive approach, we can explain the distribution of idioms in Hebrew and English, and we can also capture the structurally compositional nature of idiom formation. Although some idiom parts are discontinuous on the surface linear sequence, they form a syntactic constituent, contrary to Mishani-Uval and Siloni's claim. Besides, Mishani-Uval and Siloni's approach merely describe the distribution of 
ditransitive idioms with respect to verb types. I conclude that a structural verb-sensitive approach to dative alternation fares better than non-structural verb-sensitive approach (of Mishani-Uval and Siloni) or selection-based approach (of Breuning) in explaining ditransitive idiom patterns of Hebrew and English.26) The distribution of idioms is verb-sensitive, and it can be interpreted in structural terms. Also, idioms form a structural constituent.

\subsection{Korean}

In Hallman-style structural Verb-Sensitivity analysis of dative alternation, the DOC of Korean (i.e. [Acc-Acc] pattern) would have a structure like (40a). Under constituency-based approaches, the existence of Fixed-Theme (Open-Goal) idioms and the nonexistence of Fixed-Goal (Open-Theme) idioms are accounted for. The [Dat-Acc] pattern corresponds to the PDC, according to Y-J Jung \& Mitagawa (2004) and L Kim (2015), among others. As English PDCs have two different structures in Verb-Sensitivity analysis, we may plausibly assume that Korean also has two structures for the PDC (i.e. Dat-Acc pattern) because Korean shows the same verb sensitivity as English and Hebrew: (i) Derived PDC (40b) (Caused Possession semantics, Animate Recipient/Possessor Goal, give-type verbs) with the Goal demoted leftward27); and (ii) Base-generated PDC (40c) (Caused Motion semantics, Inanimate Spatial Goals, sendbut not give-type verbs). ${ }^{28)}$

26) As for the non-existence of Full idioms in the DOC, both constituency and selection-based approaches fail to explain it. We may have to consider L Kim or K-M Kim's (2015) claim positively as an independent restriction that Appl is a boundary delimiting idiom formation/idiomatic interpretation. I leave this problem for future research.

27) As a reviewer notes, Korean send-type verbs do not occur in the Acc-Acc pattern (i.e. the DOC). In Korean, only a small subset of ditransitive verbs with Caused Possession semantics occur in the Acc-Acc pattern. The possibility of the Acc-Acc pattern suggests that a given verb has a Caused Possession meaning, but the impossibility of the Acc-Acc pattern does not necessarily suggest that a given verb does not have a Caused Possession meaning. Although the reviewer shows skepticism for the structure (40b), I think it is still necessary for give-type verbs in the PDC whose meaning reflects Caused Possession.

28) Miyagawa and Tsujioka (2004) note the following contrast in quantifier scope. As we can see in (i), the quantifiers in the Goal-Theme order show unambiguous scope 
(40) a. DOC in Korean

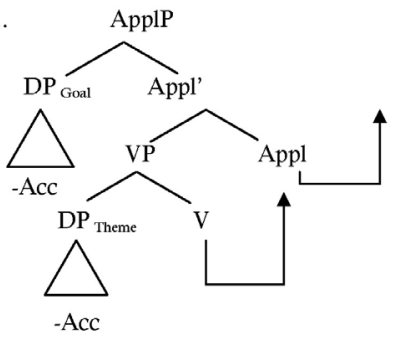

when the Goal is animate. However, ambiguity obtains in the Goal-Theme order if we use an inanimate Goal, as in (ii). In their proposal, (i) (with animate Goal) corresponds to the DOC, where the Goal is in a higher projection (in Appl) than the Theme (in VP), hence the quantifiers are scopally unambiguous, following Bruening's (2001) QR-as-subjacency analysis. (ii) (with inanimate Goal) corresponds to the PDC, which has a simpler structure, where the Goal and the Theme are generated in the same VP. Since two arguments belong to the same projection, they are equidistant to the target of $\mathrm{QR}$, yielding ambiguous scope. On the surface, both (i) and (ii) have the same Goal-Theme order, but they show different scope behaviors depending on the animacy of the Goal.

(i) Animate Goals

Taroo-ga dareka-ni dono-nimotu-mo okutta. (Goal-Theme)

Taro-Nom someone-Dat every-package sent

'Taro sent someone every package.'

(some > every, *every > some)

(ii) Inanimate Goals

$\begin{array}{lll}\text { Taroo-ga dokoka-ni dono-nimotu-mo } & \text { okutta. } \\ \text { Taro-Nom some place-to every-package } & \text { sent } \\ \text { 'Taro sent every package to some place.' } & \\ \text { (some }>\text { every, every }>\text { some) } & \end{array}$

In the case of Korean, L Kim (2015: 37) gives an example like (iii), which also shows only surface scope reading in the animate Goal-Theme order.

(iii) Hana-ka etten ai-eykey motun chayk-ul cwu-ess-ta. Hana-Nom some kid-Dat every-book-Acc give-Pst-Dec 'Hana gave every book to some kid.'

(some $>$ every, *every $>$ some)

However, I suspect there is ambiguity in the following (iv), where the Goal is inanimate and the verbal head is send-type. So, I think that the position for animate and inanimate Goals may be different, as in Japanese. But, further study is necessary to make such a claim strongly.

(iv) (halmeni-ka Sumi-eykey cangsik sipcaka-lul han sangca cwu-si-ess-ta) Grandma-Nom Sumi-Dat decoration-cross-Acc one-box give-Hon-Pst-Dec 'Grandma gave a box of decoration crosses to Sumi.'

Sumi-ka etten cangso-ey motun sipcaka-ul pak-ass-ta/ponay-ess-ta. Sumi-Nom some place-Dat every cross-Acc nail-Pst-Dec/send-Pst-Dec. 'Sumi nailed/sent every cross to some place.' (some > every, every > some) 
b. PDC (=derived from DOC)

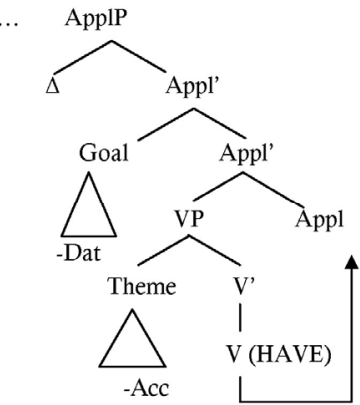

c. PDC (=base-generated PDC)

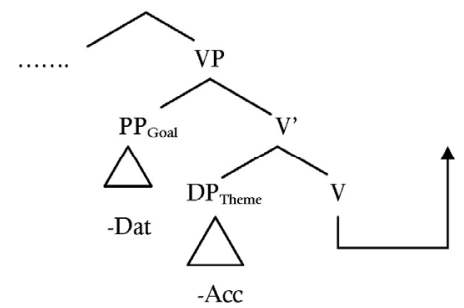

With give-type verbs, we predict to find only Fixed-Theme (Open-Goal) idioms from (40b), which is borne out. Now let's consider situations with send-type verbs and other canonical Caused Motion verbs. The prediction that we may find Full idioms (in the Goal-Theme-V order) is borne out, as the Goal, the Theme and V form a VP constituent in (40c). In the base-generated PDC structure (40c), the existence of Fixed-Theme (Open-Goal) idioms with Spatial Goals (e.g., -ey mom-ul pachi-ta, -ey mwul-ul kkien-ta, -ey yel-ul nay-ta) is also correctly predicted.

However, we cannot explain the existence of Fixed-Goal (Open-Theme) idioms in the base-generated PDC (Caused Motion or send-type verbs with Spatial Goals), because in the given structure (40c) the Goal argument does not form a constituent with V. Under the assumption that what is interpreted as a (rigid) idiomatic unit must be projected as a syntactic constituent (Chomsky 1980, Larson 1988, Harley 2002, and others), the presence of Fixed-Goal (Open-Theme) idioms supports the base-generation approach for another PDC structure in which the Theme is generated higher than the Goal. Therefore, I propose to adopt Miyagawa 
and Tsujioka's (2004) base-generation hypothesis for the word order permutation between the Goal and the Theme in Japanese ditransitives. (See also Tsujioka 2011 and Miyagawa 2012.) Miyagawa and Tsujioka's claim is that a Spatial/locative Goal (i.e. "low goal" in their terminology) selected by ditransitive verbs may occur either to the right or the left of the Theme, whereas a Recipient/Possessor Goal (what they call "high goal") is always placed in a higher position than the Theme and the Low Goal. This claim can be schematized as (41) with a tree diagram in (42). In their proposal, the Goal-Theme order may be the DOC if the Goal is animate, but it has to be the PDC if the Goal is inanimate that cannot be construed as the Recipient/Possessor.

(41) Two Goal Hypothesis (Miyagawa \& Tsujioka 2004)

a. high goal (possessor) … low goal (locative) ... .. theme

b. high goal (possessor) … theme $\cdots$. low goal (locative)

(42)

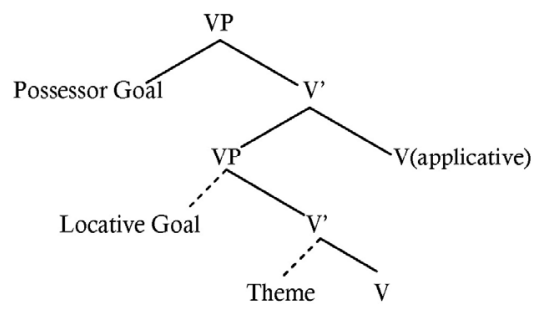

High Goals (i.e. Recipient/Possessor) are always merged higher than the Theme, whereas Low Goals (i.e. Spatial/locative) can be merged either higher or lower than the Theme as indicated by the dashed lines.

Under the assumption that idioms are assigned their interpretation in the basic constituent order, the availability of Fixed-Goal (Open-Theme) idioms now suggests that the Theme-Goal order in the base-generated PDC is not derived through scrambling but is another base-generated structure. In other words, Spatial Goals can be base-generated either above or below the Theme position in Korean. ${ }^{29)}$

29) A reviewer points out that there are two subtypes of send-type verbs in Korean in terms of the position of the Goal in the current proposal, and asks whether send-type verbs in the two subtypes have any difference in interpretation. In (26), we can see 
As for Japanese ditransitive idioms that may have both Goal-V and Theme-V patterns (i.e. Fixed-Goal and Fixed-Theme), Kishimoto (2008:144) notes that "while data arguing for the structure of ditransitive verbs in Japanese often need subtle judgments and/or are subject to idiolectal variations and fuzziness (see, e.g., Kitagawa 1994), Miyagawa and Tsujioka provide fairly clear idiomatic data in support of their base-generation claim." Accepting Miyagawa and Tsujioka's claim that there are two positions for Low Goals, however, Kishimoto (2008) argues that the Low Goal position below the Theme (i.e. in the Theme-Low Goal order) is only for idioms, i.e. it is an idiomatic Goal position, based on the facts regarding nominalizations and case marking. There is a debate regarding this lowest Goal position below the Theme in Japanese, whether this position is only for idiomatic Goals or for both idiomatic and ordinary Goals (e.g., Kishomoto 2008 vs. Tsujioka 2011 and Miyagwa 2012). The same problem arises for Korean too. Since I have not been able to find evidence for Kishimoto-style analysis in Korean, I will leave it for future research, although I suspect that Kishimoto's position is favorable than Miyagawa and Tsujioka's. Leaving the question aside, I will just conclude here that the existence of the Theme-Goal order in Fixed-Goal (Open-Theme) idioms allows us to posit two different base-generated orders between the Theme and the Goal (Spatial, low Goal) in the base-generated PDC.30)

that the send-type verbs participating in Fixed-Goal (Open-Theme) idioms with the $\mathrm{Acc}_{\text {Theme}}-\mathrm{Dat}_{\mathrm{Goal}}$ order are mol-ta ('drive') and ponay-ta ('send'). These verbs belong to verbs of motion and require PATH component in meaning. The availability of -eykey-lo and -lo marking (i.e. spatial goal marker -lo) for animate and inanimate Goals, respectively, shows the point. It may be that the Goal argument with strong directional meaning needs to be closer to the $\mathrm{V}$ than the Theme. On the other hand, the send-type verbs in Full idioms with the Dat ${ }_{\text {Goal }}-\mathrm{Acc}_{\text {Theme }}$ order are pak-ta ('hammer') and pwus-ta ('pour'). These verbs do not allow the spatial goal marker -lo (i.e. ${ }^{*}$ eykey-lo, *-lo), showing that they do not have an inherent PATH component in meaning (i.e. they are not verbs of motion). English verbs hammer and pour appear in spray-load alternation. It is not clear to me at this point whether Korean counterparts show a similar locative alternation. I leave it as a future research topic to characterize send-type verbs with different word order in terms of their meaning.

30) What remains puzzling is the nonexistence of Full idioms in the Theme-Goal-V order, then. One may ask whether the Goal-Theme order is the basic underlying structure (as the order of Full idioms suggests) and the Theme-Goal order in Fixed-Goal (Open-Theme) idioms reflect information-structure sensitivity (such as animacy, referentiality, giveness, etc.). Some claim that the dative alternation is subject to a general tendency for animates to precede inanimates, given material tends to precede new 


\subsection{Section Summary}

In section 5, we have seen that a constituency-based approach can account for the distribution of ditransitive idioms in Korean, Hebrew, and English once we adopt structurally implemented Verb-Sensitivity approach to dative alternation between the PDC and the DOC. The constituency-based analysis of idioms has an important implication for the internal structure of ditransitive verb phrases and the word order permutation for languages like Korean.

\section{Conclusion}

In this paper, I described and examined Korean ditransitive idioms in comparison with Hebrew and English in terms of the following criteria: the distribution of fixed- and open-slots, verb types, argument structure types, and the word order. The paper supports the claim that ditransitive verbs are not all uniform, and they can be classified into give-type verbs and send-type verbs in both non-idiomatic and idiomatic contexts. Fixed-Goal (Open-Theme) idioms and Full idioms only occur in Caused Motion event schema (with send-type verbs). In the case of Fixed-Theme (Open-Goal) idioms, only give-type verbs with animate Recipient Goals that denote Caused Possession meaning are found in Hebrew and English.

material, and definite/referential element precedes indefinite/nonreferential elements, etc. For Korean, H-W Choi (2008) discusses information structural constraints in the word order permutation between the [Dative Goal-Accusative Theme] order and the [Accusative Theme-Dative Goal] order. She found that animacy and pronominality are not factors, but givenness/newness is in that the 'given before new' order is much preferred to 'new before given' order. In the case of both Fixed-Goal (Open-Theme) idioms and Fixed-Theme (Open-Goal) idioms, not only 'inanimate>inanimate', 'nonreferential > nonreferenial' orderings, but also 'animate>inanimate' 'referential $>$ nonreferential' orderings are observed (e.g. sengkong-ul nwunaph-ey twu-ta, yakcatul-ul/ku salam-ul sonakwi-ey cwi-ta, minyetul-eykey/Mary-eykey hannwun-ul palta, kyehoyk-ey pakcha-lul kaha-ta, etc.). Full idioms always occur in 'inanimate>ianimate' or 'nonreferential/nonreferential' pattern. So, Fixed-Goal (Open-Theme) idioms may be available in the Theme-Goal order to host 'referential Theme>nonreferential Goal.' Although information structural constraint might be working, I go for the structural constituency analysis in the paper as it explains idiom facts across languages in a uniform manner. Surely, this is an important challenge for future study. 
I have found out that Korean is more liberal in allowing both send- and give-type verbs. What is common across three languages is that give-type verbs only occur in Fixed-Theme (Open-Goal) idioms, and not in Fixed-Goal (Open-Theme) or Full idioms.

Regarding this data set, I have provided a unified account for the distribution of different types of ditransitive idioms in three languages by adopting Rappaport Hovav and Levin's (2008) Verb-Sensitivity approach and Hallman's (2015) structural implementation of it, in which two different structures are posited for the PDC of English and Hebrew and for the [Dat-Acc] pattern of Korean (which has been assumed to correspond to the PDC). The present paper also has a consequence for theories of idioms, as it provides support for constituency-based approaches to idiom formation. The paper also suggested that Spatial Goals can be generated either above or below the Theme in languages like Korean. I hope that a future study will examine whether it is just for idiomatic Goals or for ordinary Goals as well.

\section{References}

Bruening, Benjamin. (2001). QR obeys superiority: ACD and frozen scope. Linguistic Inquiry 32.2, 233-273.

(2010). Ditransitive asymmetries and a theory of idiom formation. Linguistic Inquiry 41.4, 519-562.

Cho, Jai-Hyoung. (1994). Scrambling: Crossover, Reconstruction, and Binding Theory. Doctoral dissertation, University of Connecticut.

Choi, Hye-Won. (1999). Optimizing Structure in Context. CSLI, Stanford. (2008). Beyond grammatical weight: a corpus study of information structure effect on dative-accusative order in Korean. Discourse and Cognition 15.3, 127-152.

Chomsky, Noam. (1980). Rules and Representations. New York: Columbia University Press.

Cuervo, Maria Cristina. (2003). Datives at Large. Doctoral dissertation, MIT.

Emonds, Joseph. (1972). Evidence that indirect object movement is a structure-preserving rule. Foundations of Language 8, 546-561.

Francez, Itamar. (2006). Possessors, goals and the classification of ditransitive predicates: evidence from Hebrew. In Empirical Issues in Syntax and Semantics 6: 
Papers from CSSP 2005, ed. By Olivier Bonami and Patricia Cabredo Hofherr, 137-154. Paris: Colloque de Syntaxe et Semantique à Paris.

Hallman, Peter. (2015). Syntactic neutralization in double object constructions. Linguistic Inquiry 46.3, 389-424.

Harley, Heidi. (2002). Possession and the double object construction. Yearbook of Linguistic Variation 2, 29-68.

Harley, Heidi and Shigeru Miyagawa. (2017). Ditransitives. To appear in Oxford Research Encyclopedia of Linguistics.

Hong, Ki-Sun. (1998). Idiomatic expressions in Korean and argument structure. Language Research 34, 547-573.

Hwang, Juhyeon. (2015). Idioms in Korean ditransitive constructions. Studies in Linguistics 37, 429-454, The Joong Won Linguistic Society of Korea.

Jeong, Youngmi. (2007). Applicatives: Structure and Interpretation from a Minimalist Perspective. John Benjamins Publishing Company.

Jung, Yeun-Jin and Shigeru Miyagawa. (2004). Decomposing ditransitive verbs. In Proceedings of Seoul International Conference On Generative Grammar, 101-120.

Kim, Kyumin. (2015). Phase-based account of idioms and its consequences. Linguistic Research 32.3, 631-670.

Kim, Lan. (2015). Asymmetric ditransitive constructions: evidence from Korean. Lingua 165, 28-69.

Kishimoto, Hideki. (2008). Ditransitive idioms and argument structure. Journal of East Asian Linguistics 17, 141-179.

Kitagawa, Yoshihisa. (1994). Shells, yolks, and scrambled e.g.s. In Proceedings of the 24th Annual Meeting of the North-Eastern Linguistic Society, ed. By Mercè Gonzàlez, vol. 24, 221-239. Amherst: GSLA, Department of Linguistics, University of Massachusetts.

Landau, Idan. (1994). Dative shift and extended VP-shell. MA thesis, Tel Aviv University.

Larson, Richard. (1988). On the double object construction. Linguistic Inquiry 19, 335-391.

Lee, Doo-won. (2004). Scope-freezing effect of QDO in IO-QDO order. Studies in Generative Grammar 14, 519-529.

Levin, Beth. (2010). The semantic bases of Japanese and Korean ditransitives. Handout. 20 $0^{\text {th }}$ Japanese/Korean Linguistics Conference, Oxford University, Oxford, UK, October 1-3, 2010.

Levinson, Lisa. (2005). 'To' in two places in the dative alternation. In Proceedings of the 28th Annual Penn Linguistics Colloquium, Penn Working Papers in Linguistics 11.1, 155-168. 
Marantz, Alec. (1993). Implications of asymmetries in double object constructions. In Theoretical Aspects of Bantu Grammar, ed. by Sam A. Mchombo, 113-150. Standford, CA: CSLI Publications.

Misahni-Uval Yael and Tal Siloni. (2016). Ditransitive idioms in Hebrew. Natural Language and Linguistic Theory. doi: 10.1007/s11049-016-9354-8.

Miyagawa, Shigeru. (2012). Case, Argument Structure, and Word Order. Routledge. Miyagawa, Shigeru and Takae Tsujioka. (2004). Argument structure and ditransitive verbs in Japanese. Journal of East Asian Linguistics 13, 1-38.

Nunberg, Geoffrey, Ivan Sag, and Thomas Wasow. (1994). Idioms. Language 70.3, 491-538.

O'Grady, William. (1998). The syntax of idioms. Natural Language and Linguistic Theory 16.2, 279-312.

Oh, Eunjeong and Maria L. Zubizarreta. (2009). A comparison of the English and Korean double object. In Reality Exploration and Discovery: Pattern Interaction in Language and Life, ed. by Uyechi,L., Wee, L.H., 185-212. CSLI Publications, Stanford, CA.

Pylkkänen, Liina. (2002). Introducing Arguments. Doctoral dissertation, MIT.

Rappaport Hovav, Malka and Beth Levin. (2008). The English dative alternation: the case for verb sensitivity. Journal of Linguistics 44, 129-167.

Richards, Norvin. (2001). An idiomatic argument for lexical decomposition. Linguistic Inquiry 32, 183-192.

Sohn, Ho-Min. (1994). Korean, Routledge, London.

Son, Minjeong. (2006). Directed motion and non-predicative path P in Korean. Nordlyd: Tromso Working Papers in Linguistics 33.2, 176-199.

Tsujioka, Takae. (2011). Idioms, mixed marking in nominalization, and the base generation hypothesis for ditransitives in Japanese. Journal of East Asian Linguistics 20.2, 117-143.

Ju-Eun Lee

Department of English Language and Literature Soongsil University

369 Sangdo-ro, Dongjak-gu, Seoul 06978, Korea

Email: jlee@ssu.ac.kr

Received: February 16, 2017

Revised version received: April 2, 2017

Accepted: April 6, 2017 
